\title{
Competencias ciudadanas: Representaciones sociales y prácticas pedagógicas en las Unidades Tecnológicas de Santander - UTS
}

\section{Citizenship skills: Social representations and teaching practices in Unidades Tecnológicas de Santander - UTS}

\author{
Sandra Luz Páez Clavijo \\ Especialista en Metodología de la Enseñanza del Español y la Literatura \\ Magíster (c) en Práctica Docente Universidad Pontificia Bolivariana \\ sandrapaezclavijo@gmail.com
}

Recibido: 25 de febrero 25 de 2016; Aprobado: 26 de abril de 2016

\begin{abstract}
Cómo citar este artículo:
Páez, S.L. (2016). Competencias ciudadanas: Representaciones sociales y prácticas pedagógicas en las Unidades Tecnológicas de Santander. Espiral, Revista de Docencia e Investigación, 6(1) 59 - 90.
\end{abstract}

\section{Resumen}

Objetivo y tipología textual. El presente artículo de investigación se deriva del macroproyecto Educación y Pedagogía para la Paz, de la Maestría en Práctica Pedagógica -V cohorte- de la Universidad Francisco de Paula Santander, seccional Cúcuta. Tiene como objetivo configurar las competencias ciudadanas a partir de las representaciones sociales de estudiantes y docentes de educación superior, así como del análisis de las prácticas pedagógicas de los mismos.

Metodología. Como parte del horizonte metodológico se seleccionó el enfoque cualitativo por cuanto facilita la observación rigurosa de las particularidades de las prácticas pedagógicas explícitas y latentes, así como los significados que les dan los actores que las implementan; de forma coherente con el enfoque, se seleccionó el método hermenéutico como carta de navegación del proyecto e instrumentos como la entrevista semiestructurada, los grupos focales y la observación no participante para el proceso de recolección de información. El proceso de análisis e interpretación partió de cuatro precategorías que engloban los ámbitos de formación ciudadana contemplados por los Estándares de Competencias Ciudadanas del MEN: 1. Convivencia y paz; 2 . Participación y responsabilidad democrática; 3. Pluralidad, identidad y valoración de las diferencias.

Resultados y conclusiones. Entre los hallazgos preliminares puede mencionarse que, a partir de las precategorías seleccionadas, fue posible identificar que las concepciones presentes en las prácticas pedagógicas se enmarcan en combinaciones entre las dimensiones para la acción ciudadana, con predominio de las dimensiones cognitiva y comunicativa.

\section{Palabras clave}

Competencias ciudadanas, formación ciudadana, práctica pedagógica, representaciones sociales, convivencia.

\begin{abstract}
This research article is derived from the Macro Project Education and Pedagogy for Peace in the Master of Pedagogical Practice - cohort 5 - of Francisco de Paula Santander, a university in Cúcuta. It aims to set up citizenship skills from the social representations that higher education students and teachers have, as well as the analysis of their own pedagogical practices.

As part of the methodological horizon, the qualitative approach was chosen as it facilitates the rigorous observation of the particularities of the explicit and latent teaching practices as well as the meanings that the actors decide to give them. Consistently with the approach, the hermeneutical method was selected as a navigational chart of the project and the instruments such as semistructured interviews, focus groups and non-participant observation were selected for the information gathering process. Regarding to the process of analysis and interpretation, it departed with four categories that integrate the fields of civic education covered by the Standards of Citizenship Competences, by MEN: 1. Coexistence and peace; 2 . Participation and democratic responsibility; 3. Plurality, identity and appreciation of differences.

Among the preliminary findings, it may be mentioned that it was possible to identify that the imaginaries in teaching practices, are part of combinations between the dimensions for citizen action, with predominance of cognitive and communicative dimensions.
\end{abstract}

\section{Keywords}

Citizenship skills, citizenship education, teaching practice, social representations, Coexistence. 


\section{Introducción}

Como muchos términos utilizados en las ciencias sociales y humanas, el concepto de ciudadanía guarda diferentes concepciones de acuerdo a la ideología y el momento histórico que predomina en la sociedad, esta realidad hace compleja su definición. Según Cortina (citada por Ríos, 2000) la ciudadanía se manifiesta cuando un sujeto se siente parte de una determinada esfera social, de manera que puede inferirse que la ciudadanía es inherente a la vida en sociedad y al sentimiento de ser valorado y tratado con justicia. De otra parte, la vida en sociedad connota, de una u otra manera, la participación en la esfera pública, entonces el ejercicio de la ciudadanía también requiere del compromiso con la participación y al asumirlo, el sujeto obtiene reconocimiento social y el sentimiento de cohesión a su comunidad.

Al tratarse de una práctica social, como bien se describe en el párrafo anterior, la ciudadanía se convierte en un interés para los ámbitos encargados de cultivar los comportamientos aceptados socialmente, es decir, en una tarea que le compete a la familia, los medios de comunicación y, por supuesto, a la educación. Sin embargo, y siguiendo a Cortina (citada por Ríos, 2000, p. 119), el papel de la educación frente a la formación ciudadana exige una mayor rigurosidad, pues como sistema, tiene la responsabilidad de construir conocimientos que permitan al educando la comprensión y toma de posturas críticas frente a las experiencias y las relaciones propias con la sociedad. Una expresión de esta facultad de la educación se refleja en la gestión escolar, a partir de la generación de espacios y la promoción del diálogo y la reflexión sobre las acciones y actuaciones de docentes y estudiantes en su interacción pedagógica cotidiana; producto de estas problematizaciones surgen ideas que enriquecen el discurso didáctico del quehacer docente, así como aportes para el fortalecimiento académico, teórico y legal de la educación.
Es aquí cuando se hace visible la oportunidad de contribuir desde la academia con el estudio de los fenómenos de la vida escolar a la luz de los lineamientos curriculares planteados por la política educativa adoptada en Colombia desde el 2003; dicha reflexión gira en torno a, si lo estipulado por la norma ayuda en la formación del ciudadano que Colombia necesita, $\mathrm{o}$, si los referentes conceptuales e intencionalidades de los estándares de competencia ciudadana han sido comprendidos por los docentes y se visualizan en la práctica pedagógica en el interior de la institución educativa.

Dado que el análisis propuesto busca develar la naturaleza subjetiva de las prácticas pedagógicas, las representaciones sociales y los significados que les dan los actores que las implementan, se hace notoria la pertinencia de la investigación cualitativa como enfoque que orienta a la presente investigación. Lo anterior basado en los planteamientos de Denzin y Lincoln (1994, citados por Gurdián-Fernández, 2007), quienes la definen como multimetódica, pues "implica un enfoque interpretativo, naturalista hacia su objeto de estudio" (p. 34). En otras palabras, bajo este postulado puede afirmarse que el investigador estudia la realidad desde dentro, en su entorno natural, mientras pretende interpretar los fenómenos tal y como lo significan los actores implicados.

En coherencia con lo descrito anteriormente y como parte de la delimitación del horizonte metodológico, el presente artículo de investigación se orienta bajo el método hermenéutico, pues brinda elementos de análisis importantes para la comprensión de los significados dados a los fenómenos en un momento histórico determinado.

De otra parte, y para facilitar el análisis comparado de los hallazgos con las expectativas de la política educativa en materia de formación ciudadana, se seleccionaron tres precategorías de análisis que son afines a los estándares de competencias ciudadanas formuladas por el 
Ministerio de Educación Nacional (en adelante MEN); las precategorías son: 1. Convivencia y paz; 2. Participación y responsabilidad democrática; y 3. Pluralidad, identidad y valoración de las diferencias. Dichas precategorías se confrontan con las prácticas pedagógicas y las representaciones sociales emergentes del proceso de análisis e interpretación.

\section{Contextualización: El conflicto en las Unidades Tecnológicas de Santander}

El conflicto siempre ha estado presente en la historia de la humanidad, las motivaciones de orden religioso, racial, de género, social, política y económica, son el origen de inconciliables diferencias entre las personas. Sin embargo, conflicto y violencia no son sinónimos, por esto las manifestaciones violentas hacia los conflictos son una práctica que se busca desaprender.

El Estado colombiano promueve en la actualidad un histórico proceso de paz con organizaciones al margen de la ley que durante más de medio siglo han sido protagonistas de cruentos actos, dejando como resultado muerte, desolación y ruina. Este hecho político de la vida nacional es un referente que se traslada al ámbito educativo, para confrontarlo desde la mirada de las competencias ciudadanas y verificar qué tanto se hace en las prácticas pedagógicas para lograr una convivencia pacífica. Es aquí cuando el estudio sobre el aprendizaje escolar de la ciudadanía se muestra como una oportunidad para comprender la participación ciudadana como un acto consciente; tal y como lo señala Cox (2010), "es de primera importancia para el fortalecimiento de la educación cívica y ciudadana a través del potencial formativo de la experiencia escolar, hacer de la situación señalada, que es nueva, parte del discurso público acerca de la educación" (p. 4).

El contexto regional de Santander no escapa a esta situación, por lo tanto, desarrollar una investigación que pretende indagar la formación de competencias ciudadanas en una institu- ción de educación superior local, hará posible conocer en realidad qué se está haciendo para promover la paz en el contexto educativo, la mitigación de prácticas como el matoneo, el abordaje pacífico de las diferencias, el respeto por las normas, la tolerancia y la construcción de tejido social.

De otra parte, volver la mirada sobre las prácticas pedagógicas es reivindicar el papel del maestro como figura vital en la formación integral del estudiante, también de visibilizar el alto contenido ético del quehacer profesional y de las expectativas que sobre la educación, tienen los estudiantes. Adicionalmente, la investigación busca conocer la forma como las instituciones abordan la práctica de los valores democráticos, la participación activa y la valoración y el respeto por las diferencias.

Este último punto remite a la formación de educadores, pues al desplegar iniciativas de investigación que remitan a la formación ciudadana, se aportan elementos que fortalecerán al futuro maestro en el tratamiento de situaciones de conflicto escolar, mediante estrategias que lleven una explícita intencionalidad pedagógica, basada, como lo indica Chaux (2004) en el desarrollo de habilidades y competencias que solo se logran en la práctica cotidiana.

Para la investigación cualitativa también resulta un aporte el desarrollo de esta investigación, pues permite visibilizar la importancia del enfoque $y$, específicamente, del método hermenéutico en la lectura de los fenómenos escolares, mientras ratifica la vigencia de esas estrategias en la generación de conocimiento científico.

Ya en lo que se refiere a los aportes del estudio a la institución de educación superior, se espera que las Unidades Tecnológicas de Santander encuentren en los hallazgos elementos para fortalecer su misión de formación integral continua y permanente, en el cual se prioriza el desarrollo armónico y coherente de las dimen- 
siones del ser humano con el fin pleno de su realización en sociedad (UTS, 2016).

Finalmente, pero no por ello menos importante, el presente artículo ampliará el análisis de las estrategias de educación para la paz en la línea de investigación Paz y Convivencia de la Maestría en Práctica Pedagógica de la Universidad Francisco de Paula Santander, lo que permitirá a futuros investigadores enriquecer los abordajes de nuevos problemas de investigación, generar conocimiento cada vez más pertinente y con mayores posibilidades de aplicación en las aulas.

\section{Revisión teórica}

\section{Competencias}

Entender el significado de competencia, desde su concepto primigenio y etimológico para luego asociarlo al proceso educativo podría convertirse en una interesante tarea de investigación que bien merecería una extenuante labor académica. Sin embargo, el verdadero propósito de este recuento conceptual es analizar las diferentes posturas de varios autores que han investigado el tema, con el fin de revisar su aplicación en la formación ciudadana.

Sin desconocer la variedad de significados propia del concepto, se partirá de la proposición aristotélica retomada por Bustamante (citado por Tobón, 2006) en la cual se plantea que todos los hombres tienen las mismas facultades -capacidades para el conocimiento-, pero lo que los hace diferentes es el uso que le dan a dichas facultades (p. 62).

En una interpretación similar del concepto, Chomsky (citado por Tobón, 2006) contempla a la "competencia lingüística como una estructura mental implícita y genéticamente determinada que se ponía en acción mediante el desempeño comunicativo" (p. 2), es decir, al "uso efectivo de la capacidad lingüística en situaciones específicas". En el mismo sentido, Chomsky (citado por Tobón, 2006) sostiene que "los seres humanos pueden producir y comprender nue- vas oraciones, así como rechazar otras por no ser gramaticalmente correctas, con base en su limitada experiencia lingüística" (p. 2). Lo que significa que el lenguaje tiene un carácter creativo y generativo.

Chomsky (citado por Tobón, 2006) agrega que "la competencia lingüística se refiere por ende al conocimiento de las reglas o principios abstractos que regulan el sistema lingüístico: conocimiento que se desempeña en las actuaciones o desempeños lingüísticos" (p. 26). Si se traslada esta explicación al enfoque de la formación por competencias podría afirmarse que una vez dominadas las reglas de un sistema, el sujeto puede proponer o generar prácticas basadas en las normas del mismo para contextos específicos.

En oposición con los planteamientos de Chomsky, Hymes (citado por Tobón, 2006) propone el concepto de competencia como "el empleo efectivo del lenguaje y de la lingüística en situaciones específicas de comunicación, teniendo en cuenta las demandas del entorno" (p. 3). De esta manera, Hymes (1996) relaciona los actos de habla con contextos específicos y sostiene, a diferencia de Chomsky, que en la competencia comunicativa no se puede hablar de idealidad o invariabilidad, por el contrario, tal competencia tiene en cuenta los contextos específicos donde se dé la interacción. Bajo esta interpretación de competencia, el sujeto estaría supeditado al aprendizaje específico para desempeños o aplicaciones igualmente específicas.

Otro escenario en el que se desarrolla el concepto de competencia es el de la psicología cognitiva. En este sentido, desde mediados del siglo $X X$ se viene realizando una serie de importantes aportes a la comprensión de las competencias.

El investigador Tobón (2010) señala que:

A partir de conceptos tales como inteligencia, procesamiento de la información, procesos cognitivos, habilidades de pensamiento, estrate- 
gias cognitivas, heurísticas y esquemas, entre otros, se ha propuesto en esta área el término competencias cognitivas, referidas a procesos mediante los cuales se procesa la información acorde con las temáticas del entorno, poniéndose en acción esquemas cognitivos, técnicas y estrategias, lo cual permite al ser humano conocer, percibir, explicar, comprender e interpretar la realidad (p. 70)

Tobón añade que "en la actualidad los aportes de la psicología cognitiva al modelo de las competencias pueden organizarse fundamentalmente en tres líneas de investigación: 1. teoría de la modificabilidad cognitiva, 2. teoría de las inteligencias múltiples $y, 3$. enseñanza para la comprensión" (p. 70).

Pero, es importante tener una mirada desde el escenario de la pedagogía. En este sentido, Tobón (2010) explica que el concepto de competencias arribó a la educación formal básica por la ruta del lenguaje, a partir de la competencia lingüística y de la competencia comunicativa, dando razón a las consideraciones de Chomsky y Hymes en su momento, las cuales apuntan a asumir el estudio de la lengua y de la comunicación humana como un factor que trasciende la trasmisión de reglas y la simple memorización del significado de las palabras. Sobre este aspecto Tobón (2010) puntualiza que:

Los aportes de la lingüística junto con los aportes de la teoría del procesamiento de la información, las inteligencias múltiples y las competencias profesionales, llevaron a introducir el término en otras áreas del currículo diferentes al área de lenguaje. De este modo se consolida poco a poco el concepto de competencias básicas (competencias comunicativas, competencias matemáticas, competencias sociales, competencias en ciencias naturales, etc.) (p. 80).

Si se examina el escenario de la inteligencia emocional, se puede clarificar que "durante varias décadas se ha venido planteando la necesidad de considerar la parte emocional en la actuación humana" (Tobón, 2010, p. 81). Este autor reseña que una primera contribución de gran relevancia fue la inteligencia social establecida en 1920 por Thondike (Mestre, Guil, Carreras y Braza, 2000). Adicionalmente Tobón señala que de manera posterior se hayan las aportaciones ya descritas de Gardner (1987) sobre la inteligencia intrapsíquica e interpersonal.

Así mismo, Tobón (2010) destaca a Goleman como el que sustenta de manera magistral la importancia de la inteligencia emocional para el éxito de la vida social, laboral y empresarial, al plantear que la inteligencia emocional aporta el $80 \%$ del éxito, mientras que los factores y competencias cognitivas aportan el 20 $\%$ restante (p. 81). También reconoce que:

Goleman ha pasado en sus estudios del énfasis en la inteligencia emocional al concepto de competencias emocionales en cinco dominios (autoconciencia emocional, manejo de las emociones, automotivación, empatía y habilidades sociales) y veinticinco competencias. Después esto fue revisado (Goleman, Boyatzis y Mckee, 2002) y se propuso sólo cuatro dominios (conciencia de uno mismo, autogestión, conciencia social y gestión de las relaciones) y dieciocho competencias. Una denominación alternativa de esas competencias es propuesta por Bisquerra y Pérez (2007) con el nombre de competencias de desarrollo socio-personal, que nos parece relevante tener en cuenta, las cuales incluyen tanto las competencias de índole personal como la de índole interpersonal (p. 81).

Un abordaje diferente es propuesto por Hernández (citado por Tobón, 2006), quien señala que también deben considerarse los postulados de la psicología cultural que tienen como principal representante a Vygotsky por cuanto indican que las competencias "son acciones situadas que se definen en relación con determinados instrumentos mediadores" ( $p$. 3). Tobón concluye que "la psicología cultural le ha aportado al concepto de competencias el principio de que la mente y el aprendizaje son una construcción social y requieren de la interacción con otras personas, estando la idoneidad influenciada por el mismo (p.3). 
Tales definiciones son coincidentes entre los tres teóricos en tanto señalan a la competencia como una capacidad mental implícita, de carácter lingüístico que se evidencia en situaciones comunicativas del entorno.

\section{Las competencias desde la educación pública}

Una perspectiva diferente de competencia, se sustenta en la consideración del nivel individual de la empleabilidad y el fortalecimiento a través del reconocimiento de habilidades y destrezas para determinar cuáles deben adoptar los perfiles de formación dentro de la estructura del sistema de educación por competencias (Figuera y Rodríguez, 2008, p. 8).

De cierto modo, la concepción de Figuera y Rodríguez se complementa con la postura del Estado colombiano en tanto el MEN considera que ser competente significa saber y saber hacer. La competencia, entonces, propone poder usar el juicio en la realización de funciones o intereses, ya sean vagos o precisos; la sublevación formativa, mostrada en el modo de competencia, propone que, lo significativo no es sólo conocer, sino también saber crear. Es decir, "se trata, entonces, de que las personas puedan usar sus capacidades de manera flexible para enfrentar problemas nuevos de la vida cotidiana" (MEN, 2004, p. 7).

En este sentido, Marco (2008) apoya la postura oficial del MEN en la medida en que en las competencias por desarrollar "se elige después de un detenido análisis del contexto sociocultural al que potencialmente irían dirigidas. Eso las hace especialmente adecuadas y útiles como herramientas formativas" (p. 39). Considera también que se sitúan acentos en el ser personal de los individuos, en la construcción de la identidad de cada cual, en el auto-concepto y la autoestima, que apuntan a lo que la persona puede llegar a ser.

Bajo estos argumentos Villardón (2008) propone que la formación por competencias "es un modo de reclamar una enseñanza más práctica y útil para los estudiantes. Refuerza el planteamiento de una formación más práctica utilizando procedimientos que garantizan un aprendizaje significativo y funcional" (p. 21). De hecho, si se entiende la competencia como una formación más práctica y útil para la juventud estudiantil, es necesaria la generalización de competencias que permitan "gestionar tanto las diversas actividades de enseñanza dentro del aula como otras exigencias administrativas de la institución para tener como resultado un proceso de enseñanza-aprendizaje de calidad que responda a los requerimientos actuales de la sociedad" (Aldape, 2008, p. 16).

Un planteamiento complementario sobre las competencias como modelo educativo que encaja oportunamente en esta perspectiva teórica es el de Denyer (2009) cuando se refiere a que (las competencias) son consideradas

herramientas intelectuales para la vida, brindando posibilidades al individuo para expandir concepciones personales sobre la libertad, el rol y el cambio personal, con la finalidad de proyectar un futuro, minimizando en cambio los conocimientos disciplinarios básicos y ortodoxos, que cumplen con forjar las bases de la educación pero que no integrarían un aprendizaje según los tiempos modernos y las necesidades actuales (p. 22)

Pero,

¿Hasta qué punto una educación basada en competencias representa una mejora de los modelos existentes?, un medio notablemente eficaz para extender unos principios pedagógicos, una enseñanza más acorde a una perspectiva de formación integral, en equidad y para toda la vida, es la educación basada en competencias (Zabala y Arnau, 2007, p, 11).

En este modelo pedagógico se diferencian el perfil profesional, "(...) el perfil ciudadano y las competencias que los distinguen. La competencia desde una perspectiva general se reconoce como la capacitación necesaria para desarrollar íntegras funciones profesionales, 


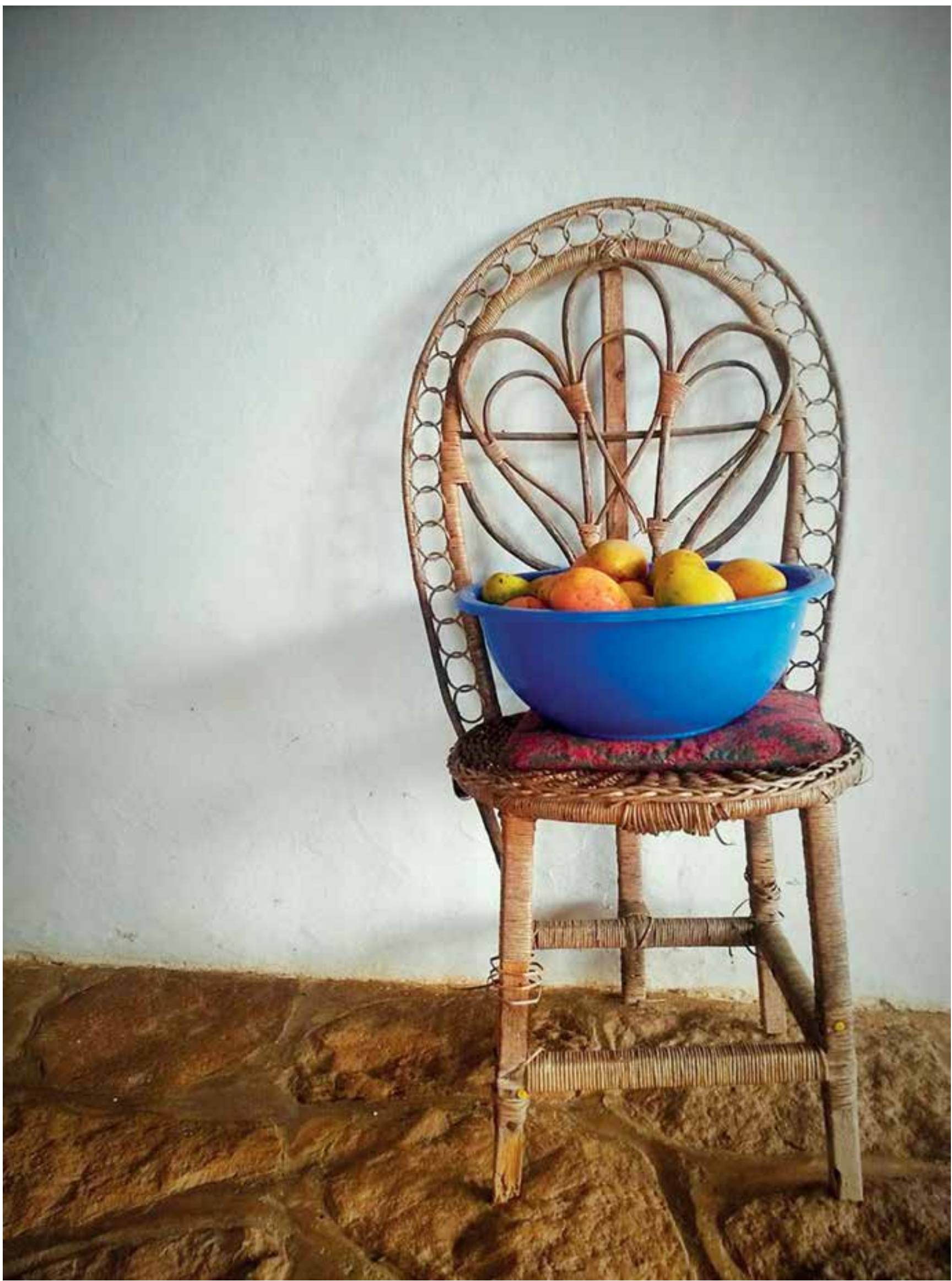


esto es el perfil formativo" (Yániz y Villardon, 2011, p. 17); es decir, este concepto concierne integridad formativa, capacidad de aprensión y necesidad de práctica para lograrlo.

Por otro lado, si logra verse el concepto de competencia "como una combinación dinámica de atributos, respecto del conocimiento y sus aplicaciones, de las actitudes y responsabilidades, que describen los objetivos de aprendizaje de un programa educativo", (Escalona y Loscertales, 2009, p. 19), se lograría enfocar, según lo dicho, al estudiante en una perspectiva futura real y práctica, pero no aplicada a la realidad actual, sino a la realidad fraguada y cambiante que el mismo alumno forja desde el aula, desde su cambio de pensamiento y sus actitudes positivas frente a su contexto inmediato. Se dan directrices para que el estudiante visualice un porvenir. La competencia es en sí, "un saber hacer en contexto, ese saber hacer comprende las implicaciones de los hechos, entender las consecuencias y asumirlas de manera responsable" (Bustos, 2010, p. 75).

Como conjunto, las competencias, se reconocen como destrezas, habilidades y condiciones. Estas en combinación dinámica

(...) aportan significativos atributos al conocimiento y su aplicación, a actitudes y responsabilidades, de tal manera que una persona es competente cuando demuestra que 'sabe', sabe hacer, sabe estar y sabe ser, con cierto nivel de calidad y de manera flexible y autónoma (Boza, Méndez, Monescillo y Toscano, 2010, p. 35).

Luego de sus aportes iniciales, Tobón (2010) complementa que no cree que el concepto de competencias venga del mundo laboral, sustenta que el concepto de competencias se estableció con base en contribuciones de "diversas fuentes, tanto en las organizaciones como en la educación y en la sociedad; respecto a los enfoques, enfatiza algunos elementos en la aplicación de las competencias" (p. 14). Sin embargo en la práctica, los enfoques no se dan pu- ros, sino que tienen ciertas combinaciones de acuerdo con su empleo (Aldana y Ruíz, 2010).

Ahora, si bien el enfoque por competencias pretende romper con los modelos educativos tradicionales caracterizados por la separación de los conocimientos, de allí su estructura disciplinar, también es cierto que en el modelo basado en competencias se habla de ejes o núcleos temáticos, que se caracterizan por la integración de conocimientos, para lo cual se requiere del trabajo interdisciplinario de los docentes y de propuestas curriculares que sean de mayor flexibilidad.

Rosario Jaramillo Franco en Altablero (2004) explica que:

La noción de competencias es muy importante porque está tratando de romper con la idea de que la educación debe atender solamente la transmisión de conocimientos. Lo que tradicionalmente se hacía en la escuela era garantizar que la nueva generación recibiera los conocimientos de la anterior. $Y$ aunque es importante, porque hay que preservar el conocimiento culturalmente establecido, lo que más importa es desarrollar habilidades de pensamiento. No basta tener el conocimiento; hay que ir más allá y usarlo para producir cosas, ideas, soluciones a problemas, buscar alternativas (p. 4).

\section{Competencias: Procesos integrales de actuación}

Hasta aquí se ha hecho un breve recuento que muestra diferentes abordajes y significados de las competencias, pero para comprender la estructuración pertinente de programas educativos basados en este modelo es importante revisar las propuestas que lo relacionan con el aprendizaje de procesos integrales para la actuación.

Tobón (2010) explica que las definiciones que de manera habitual se elaboran sobre las competencias están determinadas por la forma como focalizan los aspectos tangibles e intan- 
gibles relacionados con ellas. Un ejemplo es que

con frecuencia se entienden las competencias sociales (tienden a ser intangibles) diferentes a las competencias técnicas (tienden a ser más tangibles). Así mismo, el significado del concepto cambia entre países refiriéndose indistintamente a títulos educativos, categorías laborales, puesto de trabajo, etc. (p. 88).

A su turno Robotham y Jubb 1996 (citados por Tobón, 2010) reiteran que "el término competencias es un concepto confuso en la cultura organizacional y en educación actual". Añade Tobón (al citar a Gil, 2000) que:

en la medida en que no está claro si las competencias se refieren a lo que las personas son capaces de hacer, deben ser capaces de hacer, tienen que hacer o realmente hacen para alcanzar el éxito en un puesto o en una organización (p. 91).

Así las cosas, según Gonczi y Athanasou (1996)

(...) las competencias no podrían abordarse como comportamientos observables solamente, sino como una compleja estructura de atributos necesarios para el desempeño en situaciones diversas en las cuales se combinan conocimiento, habilidades, valores y actitudes con las tareas que se tienen que desempeñar en terminadas situaciones (Tobón, 2010, p. 91).

Desde otra perspectiva Zubiría (2002) sostiene que las competencias han sido abordadas en la educación descontextualizada paradigmáticamente hablando, dado que piensa que no se puede sacar una noción -como competencias- de un paradigma teórico, y ponerla a operacionalizar y a funcionalizar en otro. Zubiría agrega que "la idea misma de 'paradigma teórico implica que, si una categoría se saca del sistema, es necesario sacar las tesis anexas, las tesis dominantes y las subordinadas" (Zubiría, 2002, p. 55). De acuerdo con este autor, "la noción actual de competencias ha sido sacada arbitrariamente de un paradigma teórico (la lingüística) y se está aplicando a otras áreas de una forma asistemática y desconexa, sin criterios claros" (Zubiría citado por Tobón, 2010, p. 55).

Esta tesis además señala que al haber

sacado la palabra competencia sin haber reflexionado sobre la noción de teoría y sin haber tenido en cuenta el problema del concepto de paradigma, se produce una gran confusión y se da lugar a que las competencias se vuelvan un listado totalmente arbitrario de lo que sea. Eso es cinismo. Dentro de poco comenzaremos a hablar de competencia para amarrarse los zapatos, competencia para el orgasmo (Zubiría citado por Tobón, 2010, p. 56).

Respecto a esta posición, Tobón (2010) anota que "la noción de competencia que actualmente se emplea en educación no proviene de un único paradigma teórico como plantea Zubiría (2002) sino que tiene múltiples fuentes teóricas (filosofía, lingüística, sociología, psicología, educación para el trabajo, pedagogía, gestión de la calidad, inteligencia emocional, etc. (p. 92).

Agrega también Tobón (2010) que:

Efectivamente, una teoría pedagógica requiere poseer interdependencias teóricas y estar articulada a un sistema conceptual en el cual cada término sea solidario de los demás. Esto ya se ha comenzado a dar en la formación basada en competencia y al respecto se cuenta con notables avances teóricos y metodológicos desde el marco del trabajo transdisciplinario y el pensamiento complejo (p. 92).

De tal manera que en síntesis, desde la perspectiva de Tobón, "la formación integral y de las competencias requiere de la asunción de una nueva inteligencia y racionalidad que trascienda la parcelación y la fragmentación, con el fin de que aborde la realidad en su multidimensionalidad".

Así mismo: "la inteligencia parcelada, compartimentada, mecanicista, disyuntiva, reduc- 
cionista, rompe lo complejo del mundo en fragmentos separados, fracciona los problemas, separa lo que está unido, y unidimensionaliza lo multidimensional (p. 93).

Por ello, a partir de lo anterior, Tobón propone conceptualizar las competencias como:

Procesos integrales de actuación ante actividades y problemas de la vida personal, la comunidad, la sociedad, el ambiente ecológico, el contexto laboral-profesional, la ciencia, las organizaciones, el arte y la recreación, aportando a la construcción y trasformación de la realidad para lo cual se integra el saber ser (automotivación, iniciativa, valores y trabajo colaborativo con otros) con el saber conocer (conceptualizar, interpretar y argumentar) y el saber hacer ( aplicar procedimientos y estrategias) teniendo en cuenta los retos específicos del entorno, las necesidades personales de crecimiento y los procesos de incertidumbre, con espíritu de reto, idoneidad y compromiso ético (p. 93)

Luego de este recorrido teórico en el que se han revisado las posiciones de diferentes investigadores alrededor de las competencias Se da por sentado que la concepción de competencia tiene multiplicidad de interpretaciones, más aún cuando se aplican al ámbito educativo y pedagógico. Sin embargo, en términos de utilidad para el desarrollo del proyecto investigación de las representaciones sociales de las prácticas pedagógicas en competencias ciudadanas que se desarrolla en las Unidades Tecnológicas de Santander, se adoptará una definición que interpreta las competencias como procesos integrales de actuación ante actividades y problemas de la vida personal, la comunidad, la sociedad, el ambiente ecológico, el contexto laboral-profesional, la ciencia, las organizaciones, el arte y la recreación, aportando a la construcción y trasformación de la realidad para lo cual se integra el saber ser (automotivación, iniciativa, valores y trabajo colaborativo con otros) con el saber conocer (conceptualizar, interpretar y argumentar) y el saber hacer (aplicar procedimientos y estrategias) teniendo en cuenta los retos específicos del entorno, las necesidades personales de crecimiento y los procesos de incertidumbre, con espíritu de reto, idoneidad y compromiso ético.

\section{Competencias ciudadanas}

Ya en materia de formación ciudadana, cabe agregar que el término competencias ciudadanas ha sido acuñado particularmente por el Estado colombiano para referirse a la labor de educar para la ciudadanía y la cívica. De esta concepción es responsable en buena medida Enrique Chaux, investigador colombiano que asumió junto a la Asociación Colombiana de Facultades de Educación (Ascofade) la tarea de asesorar al MEN en el proceso de consolidación de los "Estándares Básicos de Competencias Ciudadanas".

Ruiz-Silva y Chaux (2005) definen a las competencias ciudadanas como "el conjunto de capacidades y habilidades cognitivas, emocionales y comunicativas -integradas- relacionadas con conocimientos básicos (contenidos, procedimientos, mecanismos) que orientan moral y políticamente nuestra acción ciudadana" ( $p$. 32). Agregan en su propuesta al MEN que "la acción ciudadana (ejercida de manera autónoma y no por imposición de otros) es el objetivo fundamental de la formación ciudadana", mientras aclaran que "para llevar a cabo una acción ciudadana es importante tener dominio sobre ciertos conocimientos, haber desarrollado ciertas competencias básicas y estar en un ambiente que favorezca la puesta en práctica de estas competencias" (p. 32). En torno a este tema Magendzo (citado por Medina y Muñoz, 2011) plantea que "la formación ciudadana debe necesariamente y de manera fundamental, reconocer que el sujeto se constituye en lo social, se asienta en una relación mutua con lo social, que accede a esta desde su cotidianidad" (p. 39). En este sentido compaginan sus percepciones en tanto ambos se refieren al mismo aspecto cuando mencionan los ambientes que favorecen la práctica de la ciudadanía de forma 
competente reconociendo al ser humano (sujeto) como un ser social. De esta manera, "la formación ciudadana está llamada a 'empoderar' a los ciudadanos, para que se apropien del mundo social, lo aprovechen y transformen, para ellos y las generaciones venideras" (Medina \& Muñoz, 2011. p. 39).

Ruiz y Chaux (citados por Mejía y Perafán, 2006) especifican que "en las competencias ciudadanas, existen otras subcategorías que permiten la acción ciudadana y las clasifican como: competencias cognitivas, competencias comunicativas y las competencias emocionales" (p. 24).

Desde un abordaje complementario, Kimlycka (citado por Mieles y Alvarado, 2012) habla del concepto de ciudadanía multicultural y en este sentido sostiene que esa ciudadanía:

(...) busca propiciar que las democracias de los estados multinacionales, multiculturales y poliétnicos construyan como fundamento constitucional el reconocimiento y apoyo a la identidad cultural de los grupos étnicos y minorías nacionales para garantizar una justicia basada en la igualdad al acceso de bienes, recursos y servicios, que se traducen en oportunidades para el despliegue de las capacidades, y en atención a las necesidades diferenciadas de los sujetos, posibilitando a los colectivos expresiones de pluralidad (p. 57).

Colombia, por ser una nación pluriétnica y multicultural dada la variedad de sus regiones, encaja en este concepto visto desde las competencias ciudadanas. Como lo anotan Mieles y Alvarado: "la historia y la cultura de cada nación y la identificación de unos valores universales que deben ser legitimados en las grandes orientaciones culturales de los países" (p. 61).

En este entorno, Chaux, Lleras y Velásquez (2004) tras sustentar teóricamente los componentes del proyecto de competencias ciudadanas y enfatizar sobre la necesidad de poner en marcha este proyecto educativo, determinaron organizarlas en tres grandes grupos. De tal ma- nera que desde el Estado se focalizaron como la necesidad de convivencia y paz; el grupo participación y responsabilidad democrática; y un tercer elemento: pluralidad, identidad y valoración de las diferencias (p. 18). Estos tres grandes grupos de competencias son los que se retoman en el presente artículo como precategorías de análisis.

Chaux et al. (2004) argumentaron su decisión de proponer esta organización de las competencias ciudadanas en Colombia, porque consideran que "vivir en sociedad y en especial en una sociedad que busca ser democrática, pacífica, equitativa e incluyente representa diversos retos" (p. 18). Al referirse de manera puntual a cada uno de los retos agregan que "por un lado está el reto de convivir pacífica y constructivamente con otros que frecuentemente tienen intereses que riñen con los nuestros". Adicionalmente "está el reto de construir colectivamente acuerdos y consensos sobre normas y decisiones que nos rigen a todos y que deben favorecer el bien común". Y, finalmente "el ejercicio de la ciudadanía implica el reto de construir sociedad a partir de la diferencia, es decir, del hecho de que a pesar de que compartimos la misma naturaleza humana, somos diferentes en muchas maneras" (p. 18).

En concordancia con esto, en el rastreo hecho para la construcción del horizonte teórico en torno al tema, se han hallado posiciones complementarias como la sustentada por Soriano (2006) cuando sostiene que competencia es "la capacidad que tiene la persona de actuar eficazmente en un tipo definido de situaciones, es decir, son conocimientos hechos práctica". Soriano además cita a Mockus (2004) para enfatizar que "las más valiosas son las integradoras, las que combinan conocimiento, emoción y comunicación" (p. 121).

En concreto, las competencias ciudadanas se pueden definir como "el conjunto de habilidades cognitivas, emocionales y comunicativas, conocimientos y actitudes que, articulados 
entre sí, hacen posible que el ciudadano actúe de manera constructiva en la sociedad democrática" Mockus, 2004, p. 2 (citado por Soriano, 2006, p. 121).

\section{Soriano adicionalmente considera que:}

Un buen ciudadano, un ciudadano competente, es quien sabe y tiene un conjunto de habilidades, conocimientos, disposiciones y actitudes favorables al desarrollo de la ciudadanía, que facilitan y propician su propia participación como ciudadano y también los procesos colectivos de construcción de ciudadanía (p. 121).

Pero la noción de competencia ciudadana no es justificada solo desde la perspectiva oficial a partir de unos objetivos meramente educacionales sino que un factor vinculante de la ciudadanía se refiere "fundamentalmente a la titularidad que un sujeto posee de determinados derechos. Ser ciudadano es respetar los derechos de los demás" (Restrepo, 2006, p. 164).

Por ello Restrepo afirma que "detrás de esta acepción aparece la discusión con respecto a la ciudadanía y la legalidad o, en otras palabras, entre el ser, el saber y el hacer ciudadano frente a la obediencia a la ley". Restrepo se muestra de acuerdo con Mockus (2004) cuando afirma que "el que obedece la ley y se ve protegido por ella, participa, respeta las decisiones tomadas de manera colectiva, se autorregula y sabe que el bien público prima sobre el privado" (p. 164).

Cuando se hace referencia a la ley, y al respeto que por ella debe darse en cualquier individuo, entra a tener plena validez la apreciación de que "la educación es una práctica eminentemente política, de allí la imposibilidad de implementar una pedagogía neutral, pues en el fondo no hay nada neutro" (Vélez, 2011, p. 97).

La autora agrega que:

(...) las carencias de los docentes para atender con plena solvencia la formación ciudadana en los términos de una ciudadanía participativa, democrática, responsable y crítica emanan no sólo de la poca atención que el tema recibe en las instituciones formadoras de maestros en los programas de perfeccionamiento docente sino, adicionalmente, de los escasos espacios que los docentes tienen en las escuelas y colegios para debatir temas ciudadanos, confrontar ideas en torno a los nuevos significados de la ciudadanía activa y de su papel, con una actitud crítica, y de preguntarse por la relación que existe entre el conocimiento y el poder, entre la educación y la sociedad, entre la educación y la práctica, entre la educación y la ciudadanía política, democráticamente ética y moral (Vélez, 2011, p. 100).

Echavarría (2008) en su tesis deja ver un elemento que concatena parte de su postura con Vélez cuando aborda el tema político. Menciona "tres perspectivas de lectura de la educación ciudadana -que-nos muestra que se trata de un tema de gran relevancia social, ética y política, en tanto delinea los aspectos de orden formativo requeridos para el fortalecimiento del ejercicio ciudadano" (p. 52). Marca un especial acento entre los modos de apropiación de los saberes políticos (...)

Analizadas las múltiples visiones que de competencias ciudadanas tienen diferentes autores tanto en el orden nacional como internacional, podría entenderse el tema de la formación en este ámbito del ser humano como un asunto político. Entendido lo político, como el conjunto de instituciones, normas, personas, y espacios físicos y espirituales que conducen indefectiblemente a una convivencia pacífica que involucra otros elementos comprendidos desde la democracia, las diferencias y la participación, entre otros.

Delgado y Vasco (2003) apoyan esta postura cuando afirman que:

(...) para alcanzar un mayor entendimiento sobre las relaciones e implicaciones entre las renovadas expresiones de lo político, la política, lo público, la ciudadanía y la formación de aquellas capacidades y habilidades individuales, colectivas e institucionales alrededor de las cuales se construirían las competencias ciudadanas, es perentorio el diseño concertado de un modelo de pedagogía social que trascienda los planos normalizados de la capacitación formal centrada en el individuo-líder aislado y solitario (p. 12). 


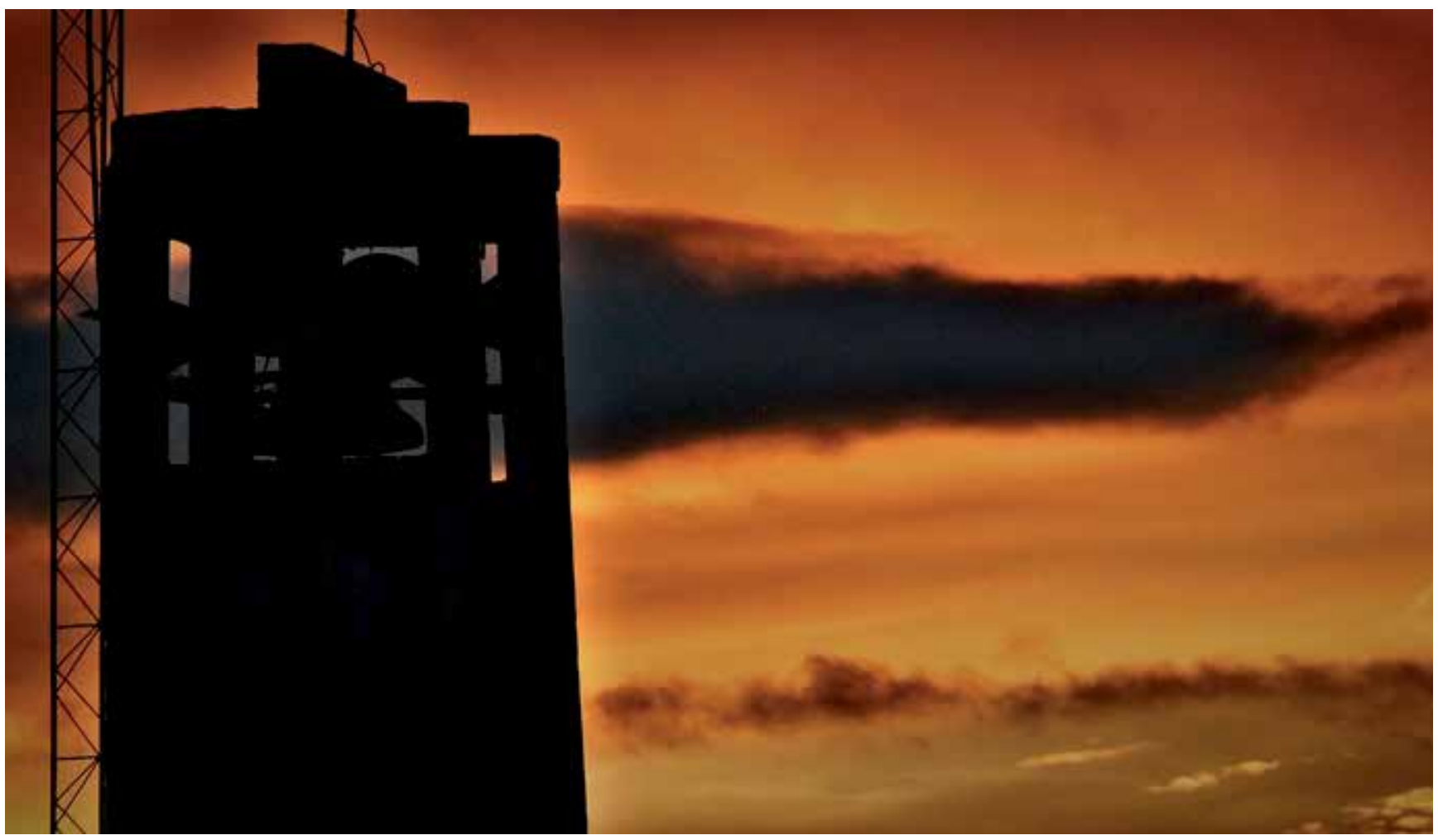

Para Ruíz-Silva y Chaux (2005) "Las competencias ciudadanas se evidencian en la práctica y en el ejercicio de la ciudadanía. Por consecuencia, la acción ciudadana es la intención fundamental de la formación ciudadana" ( $p$. 32). Es además necesario tener claro que "Desarrollar en todas y todos los estudiantes las habilidades, los conocimientos y las destrezas necesarias para construir una ciudadanía democrática y activa, es un reto fundamental en todo proceso formativo (...)" (Campo-MEN, 2011, Intro).

\section{Precategorías que engloban los ámbitos de formación ciudadana}

\section{Convivencia y paz}

Una vez presentado el contexto de la formación para la ciudadanía en Colombia, es importante realizar un breve recuento de los planteamientos teóricos que sustentan las tres precategorías ubicadas en este proyecto de investigación. Para ello se inicia con la precategoría Convivencia y Paz, de la cual se describen sus principales concepciones y abordajes.
Desde la perspectiva oficial del Estado colombiano, la educación es un camino fundamental para la paz. Sin embargo, al concretar un poco más lo que se entiende por "paz", el Estado enfatiza que la convivencia mantiene un vínculo directo con ella, pues "se basa en la consideración de los demás y, especialmente, en la consideración de cada persona como ser humano" (MEN, 2004, p. 12). Es así como la convivencia, que escuetamente podría interpretarse como habitar un lugar con otros, de cierta manera pierde su sentido neutral para definirse como la vivencia pacífica orientada hacia la resolución constructiva de conflictos.

\section{Participación y responsabilidad democrática}

La postura oficial del Estado colombiano sobre la participación la vincula a la responsabilidad democrática y las entiende orientadas hacia "la toma de decisiones en diversos contextos, teniendo en cuenta que dichas decisiones deben respetar, tanto los derechos fundamentales de los individuos, como los acuerdos, las normas, las leyes y la Constitución que rigen la vida en comunidad" (Cartilla MEN, 2004, p. 12). 
Chaux et al. (2004) refuerzan esta posición al expresar que "una sociedad que quiere ser realmente democrática requiere de la participación activa y crítica de todos". En su referencia al tema agregan que "esto implica que todos sus miembros deben poder estar involucrados en la construcción de acuerdos y en la toma de decisiones tanto en el nivel macro como en el nivel micro" (p. 19). Los autores, explican que en el nivel macro, los individuos de una sociedad se hacen

partícipes por intermedio de personas o instituciones que representan sus posiciones e intereses, en sentido opuesto, a lo que acontece en una democracia representativa, en una democracia participativa, o de nivel micro, los representantes no tienen el poder último sobre las decisiones (p. 19).

Y ocurre entonces que "este ejercicio pleno de la democracia (...), más participativo que representativo, es realmente el espíritu de nuestra Constitución Política de 1991 y refleja también nuestra concepción de ciudadanía en el ámbito de participación y responsabilidad democrática" (Chaux et al., 2004, p. 19).

\section{Valoración de las diferencias sin desmedro de los derechos humanos}

En este apartado es preciso tener en cuenta lo señalado por Walzer (1996) quien explica que "la mayor parte de los Estados que conforman la sociedad internacional son Estados-Nación" (p. 42). El autor sugiere que tal concepto no significa que cuenten con poblaciones en el orden nacional, étnica o religiosamente homogéneas, considera en cambio que "en el mundo actual, la homogeneidad es algo raro, por no decir inexistente". Propone como criterio que "un único grupo dominante organiza la vida en común de modo que queden reflejadas su propia historia y cultura y que, si todo va bien, sea ese mismo grupo el que siga conformando la historia y manteniendo viva la cultura" (p. 42). De igual manera agrega que:
(...) por lo general, la tolerancia en los EstadosNación no se ejerce respecto de grupos, sino de los miembros de esos grupos, minorías sobre las que normalmente se manejan estereotipos y a las que se permite (de hecho se espera que deseen) formar asociaciones voluntarias, crear organizaciones de ayuda mutua, escuelas privadas, sociedades culturales, editoriales, etc. (p. 42).

Walzer explica que: "en principio, no se coacciona a los individuos, pero hasta muy recientemente se ejercía (...) una cierta presión para lograr que las minorías fueran asimiladas en la nación dominante, al menos en lo que respecta a las prácticas públicas" (p. 43). Cita como ejemplo que:

(...) cuando en el siglo XIX los judíos alemanes se describían a sí mismos como alemanes en la calle y judíos en su casa aspiraban, de hecho, a la obtención de una norma, emanada del EstadoNación, que hiciera de la privacidad condición necesaria para el ejercicio de la tolerancia (p. 43).

En el marco del Estado-Nación del cual habla Walzer, es inherente la necesidad de entender la existencia de la escuela como escenario adecuado para promover la valoración de las diferencias y ejercer la tolerancia, además desde una perspectiva de los derechos humanos. $Y$ es que "la escuela es también un escenario en el que se construyen las identidades tanto individuales como colectivas, es decir, los sentidos y lazos de pertenencia que construimos con unos u otros referentes culturales" (Cartilla Eduderechos, MEN, 2002, p. 21).

Es necesario comprender "así la escuela como una institución social, que forma a los niños, niñas, adolescentes y jóvenes para que tomen decisiones informadas, autónomas, responsables, placenteras y saludables que enriquezcan sus proyectos de vida" (p. 21).

El MEN delimita desde su visión de derechos humanos que

los grupos humanos en todas las épocas han creado códigos y pautas de comportamiento 
para organizar la vida en sociedad. Dichos códigos responden a los principios y valores centrales para cada cultura en un momento determinado, se componen de normas derivadas de estos principios, e incluyen derechos y deberes de los individuos y grupos (p. 21).

Es pertinente al hacer referencia a la valoración de las diferencias, identificar las particularidades que hacen que los derechos humanos tengan una forma específica de ser comprendidos. Tales especificidades se catalogan así:

- Los derechos humanos son una construcción social, enmarcada dentro de unos determinados contextos políticos y representaciones culturales, sin las cuales su existencia habría sido impensable.

- Su carácter es universal. Hoy en día, nadie parece dudar de su validez y papel en la construcción de sociedades democráticas y pacíficas, respetuosas de la dignidad inherente a cada uno de nosotros, en las que los seres humanos nos reconozcamos como iguales en medio de las diferencias, y en las que promovamos la libertad de crear y transformar el mundo para nuestro beneficio tanto individual como colectivo.

- Los derechos humanos son un código de conducta por el cual tanto los Estados como la comunidad internacional y los ciudadanos debemos regir nuestras acciones. Esto ha implicado, a su vez, que este conjunto de valores se haya positivizado.

- Todos los derechos consagrados en cada una de las tres generaciones de derechos son considerados inalienables, interdependientes e indivisibles. Es decir, que todos los seres humanos somos poseedores de dichos derechos desde el momento en que venimos al mundo, sin importar nuestro origen, ni la clase social a la que pertenecemos, ni el grupo étnico o racial del cual hacemos parte, ni el sexo que nos tocó al nacer, ni la creencia religiosa por la que optemos. Además, ninguno de los derechos puede ser quitado a nadie por nadie y todos son condición para que los demás puedan gozarse y ejercerse.

- Al ser una construcción social, ligada a un tiempo y a unas condiciones sociales, económicas, políticas y culturales, son mucho más que un documento de buenas intenciones. Ellos están enraizados en nuestras concepciones sobre lo que somos y merecemos como seres humanos y en las aspiraciones y sueños que construimos para nuestras sociedades (Cartilla Eduderechos, MEN, 2004, pp. 21-22).

Por su parte, desde la perspectiva de equidad de género, Panchón (2007) señala que aún hoy, "el centro educativo recibe y reproduce una cultura androcéntrica, en la que es muy difícil incorporar los puntos de vista y los saberes femeninos", sostiene además que "la escuela sigue siendo todavía una realidad insuficientemente equitativa para las niñas y las adolescentes, en la que aún no se ha conseguido la eliminación de los estereotipos de género" pero aclara que "el primer entorno de responsabilidad educativa es la familia" (p. 159).

Panchón, otorga la necesidad de "una profunda reflexión sobre el sistema educativo, la organización de los centros educativos, los contenidos que se imparten, los materiales de las diferentes asignaturas y la formación del profesorado". En este sentido, deposita en los docentes una enorme responsabilidad cuando escribe que "la implicación corporativa de los profesionales de la enseñanza va más allá de las posturas personales de algunos profesores y profesoras" (p. 159).

Bajo estos planteamientos puede entenderse que aspectos aparentemente de diferente naturaleza, como la pluralidad, la identidad y la valoración de las diferencias están finamente hilados y guardan total coherencia con los derechos humanos. De igual manera, asumen 
la formación de estos aspectos como una tarea interdependiente y complementaria de la familia y la escuela, que supera las creencias o filiaciones ideológicas de los miembros de estas instituciones y deben empezar a entenderse como un compromiso fundamental para la consolidación del proyecto de Estado-Nación.

Al contrastar esta postura con la aceptada de manera oficial por el MEN, se encuentra la definición de Chaux y otros (2004) quienes explican que "la pluralidad y la valoración de las diferencias es en últimas el reconocimiento, el respeto y la valoración de las múltiples identidades propias y las de los demás" y agregan que "la pluralidad y la valoración de las diferencias no pueden llevar a que se tolere a quienes vulneran derechos fundamentales" (p. 20).

\section{Metodología}

\section{Enfoque y método de investigación}

Dado que desde el inicio de este documento se ha insistido en la construcción de sociedad y de conocimiento como un proceso dinámico, en el que intervienen todas las dimensiones sociales, y teniendo en cuenta la relación con el objeto de estudio que se plantea, para el lector no debe ser una sorpresa cuando se declara al enfoque cualitativo como la carta orientadora seleccionada. Sobre este aspecto es importante aclarar, que al reconocer las subjetividades como una forma válida de revaluar y construir conocimiento no se está favoreciendo la atomización y relativización de la realidad bajo el pretexto de la complejidad social o cultural. Por el contrario, la comprensión de los fenómenos y su manifestación en contextos específicos enriquecen la mirada del investigador para identificar, aún en entornos masificados, la presencia de dinámicas sutilmente expresadas, de manifestaciones y sentires de las minorías sociales, e incluso de concepciones y prácticas invisibles para pensamiento homogeneizador.

En coherencia con lo anterior y teniendo en cuenta que el imaginario de la investigación se retoma como un proceso de observación riguroso, similar a la multiplicidad de lecturas (de contexto, de discursos, de dinámicas), para esta investigación se identifica al método hermenéutico como el más pertinente para abordar el objeto de estudio.

\section{Muestreo}

El muestreo implementado fue por conveniencia. En primer lugar, fue necesario ubicar a profesores de las Unidades Tecnológicas de Santander (UTS) que tuvieran conocimiento de la investigación que se estaba implementando. Posteriormente, se realizaron varias conversaciones informales en las que se despejaron inquietudes y temores a la exposición de las prácticas pedagógicas.

De otra parte, se consideró necesaria la participación de estudiantes, con el fin de dar una mirada amplia a la práctica pedagógica del docente. La selección de los estudiantes se hizo, de igual manera por conveniencia, teniendo como criterios la voluntariedad y disponibilidad de tiempo de los estudiantes.

Como consecuencia de la situación planteada, la presente investigación contó con la participación de 5 profesores de las UTS que desarrollan asignaturas relacionadas con la formación integral de estudiantes cuyo perfil es tecnológico y profesional. Las asignaturas que orientan los profesores son: Ciencia, tecnología y sociedad; Cátedra UTS; Taller de Lectoescritura; Problemas sociales contemporáneos; y Habilidades comunicativas y ética. Entre los hallazgos preliminares puede mencionarse que a partir de las precategorías seleccionadas como carta orientadora del análisis fue posible identificar que las concepciones presentes en las prácticas pedagógicas de los profesores, objeto de estudio, se enmarcan en combinaciones entre las dimensiones para la acción ciudadana. De antemano este hallazgo evidencia la predominancia del discurso pedagógico en 
la configuración de la identidad docente y, por supuesto, en el aula.

Para aportar la comprensión de estas concepciones, se incluyeron en la población objetivo cinco estudiantes de diferentes programas académicos de las UTS, con el criterio de estar matriculados en las asignaturas de los cinco profesores objetivo. Esta valiosa decisión amplió la mirada sobre la práctica pedagógica, enriqueciéndola con los actores de relación directa con el profesor.

\section{Técnicas de recolección de la información}

De manera complementaria, se seleccionaron instrumentos de recolección como la entrevista semi-estructurada dirigida a profesores, grupos focales de profesores y de estudiantes y observaciones no participantes de clases. La aplicación de los grupos focales se hizo por separado a docentes y estudiantes. Aquí cabe agregar que el ejercicio profesional también tiene una esfera pública y una privada, y que las prácticas pedagógicas son percibidas por la mayoría de los profesores como una característica íntima y definitoria de su identidad profesional. Por lo anterior no es fácil, ni usual, la apertura del aula para que sujetos externos (en este caso el investigador) observe. Teniendo en cuenta esta particularidad, fue necesario invertir la aplicación de los instrumentos de recolección de información, de cómo normalmente se implementarían, para establecer un ambiente de confianza con los profesores sujeto de estudio.

Por lo anterior, el primer instrumento de recolección de información implementado fue la entrevista semi-estructurada, la cual estaba compuesta por 17 preguntas orientadoras que se clasifican en las siguientes temáticas:

- Sobre conceptos propios la formación ciudadana.

- Sobre su propio rol en la formación ciudadana.
- Sobre la promoción de los principios democráticos con los estudiantes.

- Sobre el manejo de situaciones que amenazan el ejercicio de los principios democráticos.

- Sobre pluralidad, identidad y valoración de las diferencias desde la práctica docente y la vivencia estudiantil.

Esta misma clasificación sirvió para orientar la observación no participante de clases, también la dinámica de los grupos focales con estudiantes y docentes. Más tarde en el proceso de análisis, se hicieron lecturas por tópicos de las entrevistas, identificando puntos de encuentro y desencuentro en los profesores participantes.

\section{Análisis e interpretación}

Para el análisis fue importante partir por los elementos emergentes del proceso de recolección de información, sin que ello limite el surgimiento de nuevos elementos que amplíen la comprensión del fenómeno de investigación.

\section{Representaciones sobre los conceptos propios de la formación ciudadana}

Los cinco profesores que participaron como sujetos de investigación están relacionados con la formación integral de los estudiantes, mediante asignaturas que las UTS denomina "Humanísticas"; por ello surge la necesidad de indagar por el abordaje que han desarrollado en torno a conceptos vinculados a la formación ciudadana, como conflicto, pluralidad, identidad y valoración de las diferencias. Al respecto, se observa que sus concepciones pueden ser categorizadas desde las dimensiones cognitiva-comunicativa y aunque los argumentos utilizados se sustentan en referentes teóricos, sus aproximaciones evidencian baja claridad conceptual.

Para el primero de los conceptos se encontró que los profesores conciben el conflicto como un desacuerdo entre dos o más personas, 
o como una manifestación de agresión verbal o física. También denominan al conflicto como ausencia de consenso o situación fuera de lo normal que impiden a los ciudadanos sobrellevar de manera normal su cotidianidad.

Otro concepto indagado fue el de pluralidad desde el ámbito educativo, sobre el cual se enunciaron diferentes características sin presentar una definición precisa. Lo primero en destacarse fue su vínculo con la carta constitucional, pero su ausencia en las prácticas sociales. Como concepto, fue asociado a la diversidad y comparado con la equidad y la igualdad de oportunidades. También se expresó como la diferencia de características que encuentra el docente en las aulas. Pero tal vez la explicación más abstracta fue la de su funcionalidad y valor social, pues se concibe como el acceso con el mismo nivel y prioridad para todas las personas.

Pasando al concepto de identidad en el ámbito educativo se encuentra que los profesores lo asocian con la "capacidad de definir quién se es", es decir, de expresar el ser. Bajo esta concepción, la identidad se asocia con el respeto y la no vulneración de los derechos de los demás, también con asumir un rol, defender un punto de vista y sentirse perteneciente a algo. Este último punto se ejemplifica con el sentido de pertenencia a las UTS por parte de los estudiantes y desde otra perspectiva con la ausencia de "identidad educativa en el país" por la importación de modelos pedagógicos. Como expresión de la identidad, los profesores reconocen la forma de vestir, de hablar y el origen.

En todo caso, ninguno de los profesores hizo referencia al desarrollo de la identidad en el aula; más bien fue entendida como una condición con la que "viene el estudiante" y a la que hay que adaptarse. Esta postura pasiva ante la identidad puede tener un doble riesgo, en primer lugar por la subvaloración de los efectos que puede generar la práctica docente sobre la configuración de la identidad del estudiante, teniendo en cuenta sus procesos de desarrollo propios de la edad. En segundo lugar, por la desestimación de la identidad como parte fundamental de la formación ciudadana, que al asociarse con el "respeto por el ser" puede llegar a la tolerancia de actitudes y comportamientos nocivos para la construcción de sociedad.

Los conceptos explorados permiten entender la postura de los profesores estudiados ante la valoración de las diferencias. Muchas de las respuestas retoman los riesgos descritos en el párrafo anterior, pues enfatizan en el acto de "comprender que no todo el mundo piensa lo que yo pienso", el respeto por la diferencia de opiniones y la aceptación de los demás (principalmente en las relaciones con personas de identidad sexual diversa y situaciones de posconflicto).

Lo anterior evidencia que no existe una conceptualización argumentada de la diferencia ni de su valoración. Por esta razón no se percibe claridad en las respuestas de los docentes que permitan inducir su implementación en el aula de clases.

Una vez determinadas las concepciones de los profesores, surgió la necesidad de explorar las opiniones sobre las situaciones de discriminación y exclusión social. Sobre este aspecto los profesores explicaron que este tipo de situaciones se presenta porque en el imaginario colombiano tiene una alta estimación de los prejuicios sobre las personas y que estos son otra manifestación del desconocimiento del otro y de su contexto. Agregaron que desde el aula se debe trabajar para mitigar la generación de juicios apresurados sobre las personas y los contextos, pues la discriminación y exclusión social son una "injusticia, quizás la peor que se ha inventado el ser humano".

De manera complementaria, los profesores ejemplificaron una forma de exclusión social, la actitud de autocompasión y facilismo de los estudiantes que están en la base de la pi- 
rámide social. Consideran que para ellos (los estudiantes) que pueden llegar a ser una población vulnerable, el Gobierno ha implementado más recursos de capacitación que no son aprovechados.

A su vez, afirmaron que las situaciones de discriminación y exclusión social generan pésimos ambientes de aula, la conformación de grupos cerrados por fuera de la misma, predisposición negativa al aprendizaje, tendencia a la deserción, situaciones de apatía hacia la academia y como consecuencia, atraso cultural y social. Sin embargo, aclararon que estas consecuencias de la discriminación y la exclusión social no son recurrentes en las UTS, pues entre otras razones, la distribución arquitectónica de la institución permite visualizar al grueso de los estudiantes (panóptico) y por ello pueden comprobar que no se presentan este tipo de comportamientos.
Este tipo de observaciones por parte de los profesores no cuenta con sustento investigativo, pues desde el área de Bienestar Universitario no existen estudios que aborden la dinámica entre estudiantes y su relación con las tasas de deserción o fracaso académico. Sin embargo, la percepción empírica de los profesores se mantiene en que la discriminación y el fracaso no ocurren en la institución.

En relación con el mismo tema, una de las docentes expresó que existe una dinámica normalizada y aceptada de relación con los profesores nuevos en las UTS, que se manifiesta con la recarga de trabajo. Sin embargo, lo considera un comportamiento que no representa discriminación. Teniendo en cuenta este relato es posible inferir que hay formas normalizadas, aceptadas y esperadas de rechazo social que se replican tanto en los ambientes laborales como académicos que experimenta el profesor.

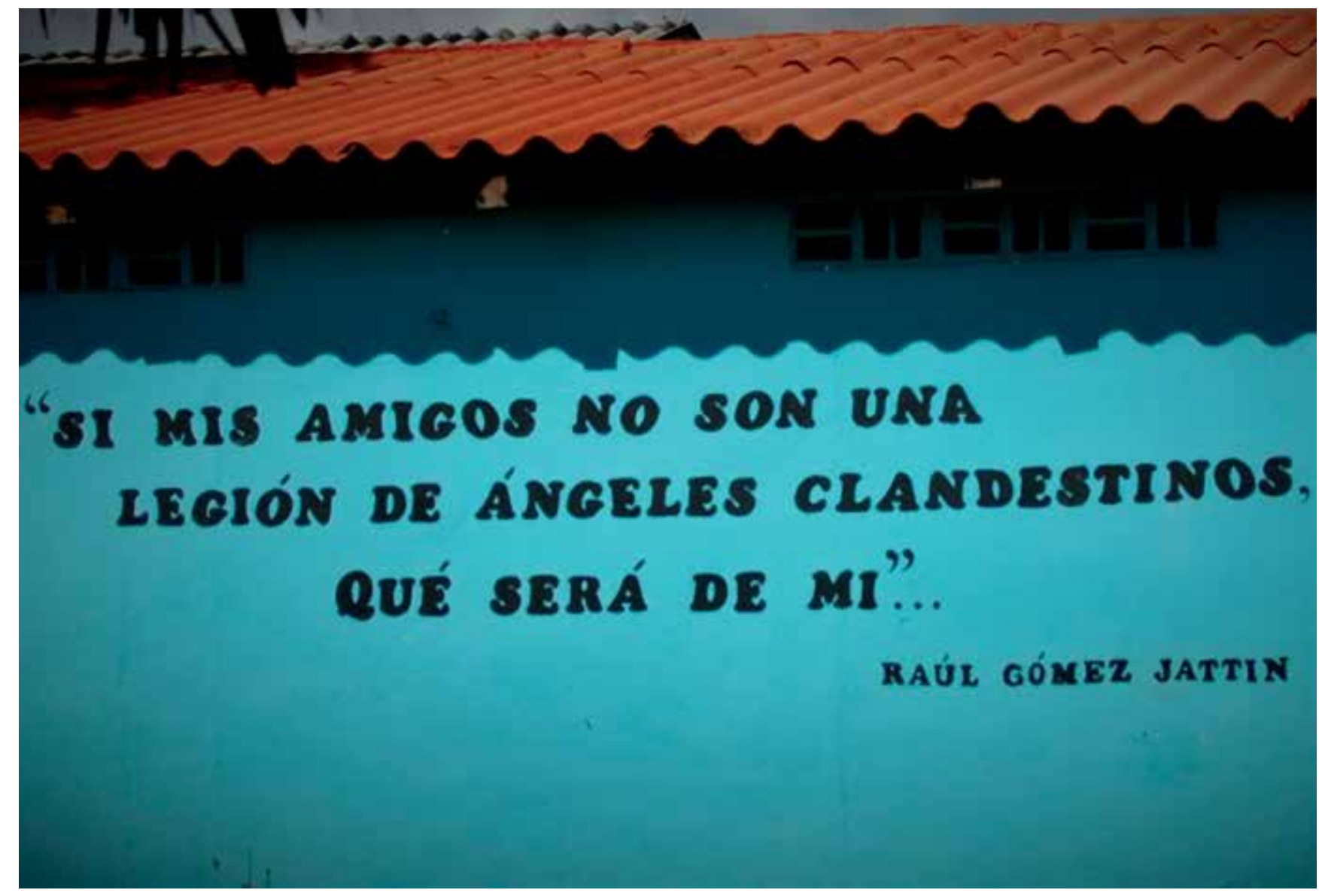




\section{Representaciones y prácticas sobre su propio rol en la formación ciudadana}

Una posición común ante las preguntas que refieren al rol y actuación propias es la sobrevaloración. Para mitigar esta postura se hizo una primera pregunta conducente a la descripción de cómo los docentes (en general) resuelven los conflictos entre los estudiantes.

Las primeras reacciones ante la pregunta señalan la incapacidad de la institución para crear ambientes armónicos y salidas negociadas al conflicto estudiantil, y como alternativa ante esta situación se propone la estructuración de contenidos que aumenten la malla curricular, específicamente la creación de una cátedra especializada en resolver conflictos. En este tipo de respuestas se puede evidenciar que los profesores desconocen alternativas reales para intervenir el conflicto desde los entornos educativos, por ello perciben que la solución ante los conflictos que se presentan entre los estudiantes parte de elementos externos a su práctica pedagógica, en este caso, la institución educativa.

Otra forma en la que abordan esta pregunta es la evasión de la responsabilidad del profesor en la mediación de conflictos entre estudiantes, principalmente, porque declaran que los docentes cuentan con aproximaciones empíricas a una "pedagogía del conflicto", también porque manifiestan no tener una formación adecuada, sumado a la inexistencia de políticas educativas institucionales y orientadoras para dirimir los conflictos dentro y fuera del aula de clases.

Sin embargo, cuando la pregunta se traslada a la esfera personal y se indaga por el rol habitual que desempeña en los procesos democráticos de los estudiantes, los profesores enlistan rápidamente sus virtudes, se consideran a sí mismos:

- Facilitador, mediador y motivador.
- Generador de criticidad susceptible a ser replicada espontáneamente en la vida cotidiana.

- Promotor de la reflexión.

- Orientador de procesos democráticos.

- Generador de análisis sobre la dicotomía correcto-incorrecto.

- Líder de opinión que resuelve dudas.

- Señalador de la demagogia.

- Mediador sin llegar a adoctrinar.

- Acompañante de la disertación sin matricularse en posturas ideológicas.

- Analista crítico de la realidad que evita la polémica.

Teniendo en cuenta estas respuestas se comprueba la premisa con la que se inicia el análisis del grupo de preguntas sobre el rol del profesor, en el cual el sujeto entrevistado sobre su propia actuación, sobrestima sus concepciones y comportamientos y se ubica en sujeto moral superior a sus pares. Desde esta mirada, el sujeto se percibe como capaz de autorregularse, motivado intrínsecamente por su comprensión de la norma, el contexto y la justicia social; mientras que sus semejantes o pares, carecen de herramientas, capacidades y voluntad para actuar correcta y éticamente.

Representaciones y prácticas sobre la promoción de los principios democráticos con los estudiantes

En apariencia, este grupo de preguntas tiene un vínculo difuso con el rol del profesor en la formación ciudadana, pero su referencia a las acciones específicas para la promoción de los principios democráticos permite determinar los recursos más utilizados en el aula de clases para superar el abordaje teórico de la ciudadanía y pasar al ejercicio de esta. 
Uno de los principios abordados es la implementación de estrategias de diálogo para la resolución de conflictos, al respecto se percibieron respuestas muy uniformes que reiteran la ausencia de formación para una adecuada resolución de conflictos y de políticas educativas relativas al tema. Sumado a lo anterior, se tiene que el término estrategia tiende a asociarse con la habilidad de la escucha y el valor del respeto, ambas desde una perspectiva intrínseca del sujeto. En consecuencia, no se contempla la necesidad de planear estrategias para la resolución de conflictos desde el diálogo, más bien esta ocurre de manera espontánea, según el estilo de cada profesor. Por lo anterior hay quienes manifiestan que existen docentes que llegan a provocar conflictos en contraste con otros que se hallan en permanente actitud de comunicación y diálogo.

Pero una mirada más detallada de estas concepciones permite entrever la construcción de la identidad docente desde el rol tradicional del profesor, en el cual se encapsula el poder y dominio de la palabra en el monólogo del docente. Bajo esta concepción, el profesor pierde la capacidad de diálogo con sus estudiantes, a quienes deja de percibir como interlocutores válidos para concebirlos como vasos vacíos que deben ser llenados de la sabiduría del maestro. Una concepción centrada en estas premisas es, ciertamente, nociva para el ejercicio participativo de la democracia y la construcción de la identidad, pero especialmente, para la valoración de las diferencias y el reconocimiento del otro.

En la misma línea, se indagó por la forma en la que el profesor motiva la participación en procesos democráticos del aula y de la institución. Aquí fue posible encontrar un solo docente que hace referencia al establecimiento de acuerdos de convivencia que surgen del consenso argumentado, como el uso de la palabra, de dispositivos móviles o la actitud frente a los demás. Otros profesores entrevistados se remiten directamente a la motivación a la participación en los órganos de representación es- tudiantil, principalmente mediante el discurso en el aula; hablan de elevar la autoestima del estudiante con el argumento del "privilegio" que representa tener acceso a la educación, lo que los convierte en líderes de opinión en sus familias para que estas a su vez desarrollen prácticas democráticas transparentes.

Sobre este aspecto, un profesor de la jornada nocturna manifestó su inconformidad por el aislamiento de los estudiantes de los procesos democráticos institucionales que se concentran en la jornada diurna; argumenta que los estudiantes de dicha jornada solo están interesados en aprobar satisfactoriamente las asignaturas y cumplir en su trabajo porque representa el sustento de ellos y sus familias.

Al igual que con el diálogo, el ejercicio de la participación democrática se evade como responsabilidad de la formación en el aula; aquí la evasión ocurre por la concepción centrada en la democracia desde la representación mediante órganos de gobierno. Nuevamente, el maestro desaprovecha la oportunidad de desarrollar competencias ciudadanas desde su práctica pedagógica.

De manera complementaria se preguntó por los beneficios que han implicado los procesos de participación democrática en la institución; casi de forma inmediata, los profesores entrevistados enlistan sus inconformidades con los espacios de participación representativa en las UTS:

- Uso para la exposición de quejas.

- Prioridad en los intereses individuales de los representantes sobre los intereses del grupo de representados.

- Espacios en los que la comunidad educativa no tiene poder de decisión.

Uno de los docentes entrevistados considera que existe apropiación del voto por parte de los estudiantes, y que esto los ha beneficiado 
en la medida en que ellos sienten que tienen voz en las decisiones de la institución. En contraste con lo anterior, otro docente se refiere a las prácticas de democracia representativa de los estudiantes UTS como "semilleros de malas costumbres democráticas", por cuanto no se observan resultados tangibles de la gestión de los mismos ante el Consejo Directivo.

El mismo profesor agrega que para analizar esta situación, la retoma como parte del estudio de su asignatura, y con el apoyo de este recurso didáctico examina los acontecimientos políticos de la nación. Concluye, explicando que al vivir los procesos democráticos de la institución se orienta la reflexión en los estudiantes.

Lo que hasta el momento se observa en la promoción de principios democráticos es la carencia de estrategias o de acciones que tengan continuidad en el tiempo y que permitan establecer mediciones sobre la madurez de una temática de análisis como parte del proceso de reflexión o discusión. Por lo anterior, es muy difícil anticipar el impacto real de las estrategias usadas tímidamente en el aula.

De manera complementaria a los principios democráticos presentados anteriormente, se indagó sobre la escucha de argumentos para la toma de decisiones en los procesos democráticos. Al respecto puede decirse que la escucha es vista como una habilidad que al contemplarse como un principio de formación democrática se relaciona con el propósito de "generar la cultura de escuchar a todos". No obstante, con el reconocimiento de este propósito de formación se aclara la inexistencia de una metodología diseñada por el docente para la escucha de argumentos.

Nuevamente se desliga el proceso de formación de la generación de prácticas conducentes a la valoración de las diferencias; por el contrario, la promoción de principios democráticos se vincula a la tradición del discurso y a la determinación de diferencias entre escuchar-oír:
- "Hacer caer en cuenta a los estudiantes".

- Inexistencia de metodologías diseñadas por docentes para orientar la habilidad de escuchar.

- Involucramiento del docente en los debates de los representantes, a los que invita a sus estudiantes como "oyentes".

Escucha y análisis de propuestas en distintos debates de representantes. Este segmento de preguntas cierra con la indagación sobre los espacios que genera el profesor para promover el diálogo frente a situaciones de discriminación y exclusión. Al respecto se encontraron dos grupos de profesores, de una parte están los que optan por el aula de clase mediante el análisis de las situaciones que se presentan en la misma y la inclusión de temas trasversales; otros manifiestan no definir espacios y utilizar cualquier oportunidad de relación con el estudiante para analizar situaciones emergentes.

Una estrategia docente en desuso que fue señalada en esta pregunta fue la ridiculización del estudiante que no sabe cómo responder a una pregunta del profesor, específicamente cuando se le hace pasar al tablero y es sometido al escarnio de sus compañeros de clase. Sobre esta práctica, los profesores entrevistados explican que es un ejemplo de discriminación que debería evitarse en la educación.

Representaciones y prácticas sobre el manejo de situaciones que amenazan el ejercicio de los principios democráticos

Anteriormente, los profesores entrevistados habían evadido la resolución de conflictos entre sus estudiantes, pero este grupo de preguntas pone de manifiesto situaciones específicas que exponen a los principios democráticos a su fragmentación; el objetivo es identificar las reacciones y comportamientos de los profesores ante estas situaciones específicas. 


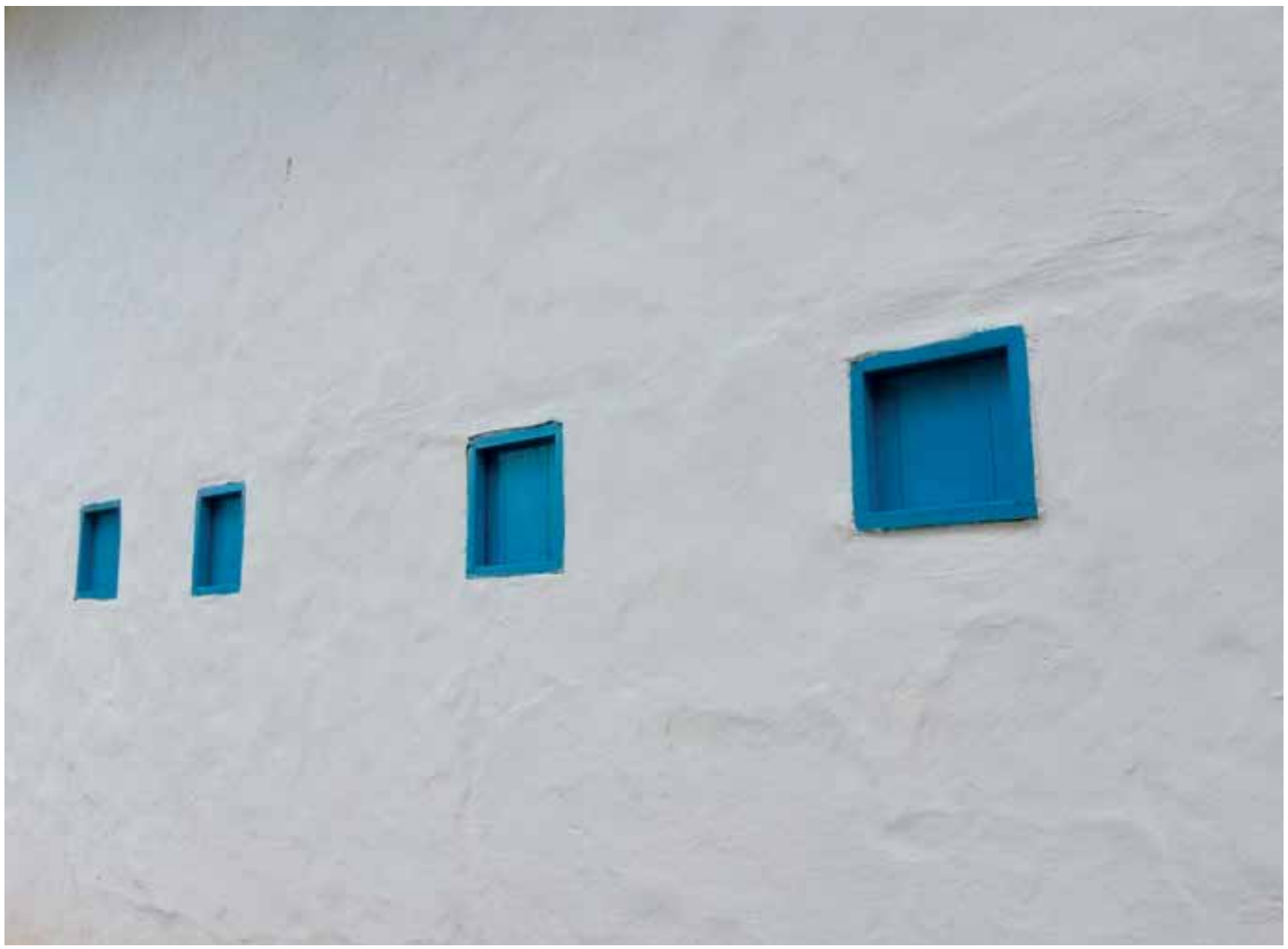

El primer escenario planteado es una situación de conflicto entre estudiantes en la que posteriormente el estudiante, por solicitud del profesor, debe justificar sus acciones. La gran mayoría de respuestas se concentra en el uso de estrategias tradicionales como la reflexión conducente al ofrecimiento de disculpas, el énfasis en los peligros de los comportamientos extremos y la negociación de los puntos de vista. Sin embargo, se observa un contrasentido en la intención de crear ambientes diversos para la expresión de ideas y el uso de métodos impositivos que buscan anular el conflicto en sí, saltando inmediatamente a la reconciliación.

De otra parte, también se observa que no se plantean los procesos necesarios para llevar al estudiante a describir y argumentar los brotes del conflicto. Esta respuesta es recurrente en todos los profesores, a excepción de uno de ellos que declaró el uso de estrategias de mediación circular, a través de la cual se construye una relación entre estudiantes que parte de la diferencia.

Otro escenario planteado fue una situación de discriminación y exclusión en la institución para indagar por las acciones del profesor ante esta. Por esta situación los profesores hicieron referencia a acciones puntuales que se enlistan a continuación:

- Orientación y motivación para el reclamo de sus derechos ante instancias formales.

- Abordaje discursivo desde la asignatura.

- Planteamiento de acuerdos (normas) de convivencia académica desde la primera sesión de clases 
- Recurrencia a los "valores" como el respeto y la tolerancia.

La actitud del docente ante este escenario responde a la tradición institucional por favorecer el acceso de estudiantes con diferentes identidades sociales, culturales y sexuales, situaciones de discapacidad y condiciones médicas que por su situación económica y bajos promedios académicos han sido rechazados en universidades de renombre de la ciudad.

Desde esta condición del contexto, para los profesores es absurda la exclusión e intolerancia en el aula de clases, razón por la que es tan importante el abordaje de la discriminación y la exclusión social como parte fundamental de la formación ciudadana.

No obstante la explicación anterior, se les preguntó a los profesores si alguna vezhabían presenciado una situación de discriminación o exclusión en el aula, y aparecieron varias situaciones de discriminación entre las que se enmarcan como las más significativas:

- El cuestionamiento de un compañero a otro por su homosexualidad.

- La ausencia de bienestar y ambiente académico para estudiantes de la jornada nocturna (aunque el profesor manifestó no estar seguro si se trata de discriminación o inequidad).

- La creencia de que en las UTS solo estudian jóvenes de estratos socio-económicos "bajos" y con dudoso desempeño académico.

- El machismo naturalizado hacia mujeres que estudian programas de ingeniería, tradicionalmente concebidos como "carreras para hombres".

Con base en lo anterior se observa que en una respuesta desprevenida sobre las situaciones de discriminación, estas se perciben desde la dimensión socio-económica. Sin embargo, una mirada más detallada sobre las diferentes características y condiciones de los estudiantes de las UTS, les permite la identificación de situaciones, por fuera de esta dimensión, que también implican la discriminación de los sujetos.

Identificadas estas situaciones se retoma la acción del profesor frente a estos escenarios, pero las acciones continúan siendo de bajo impacto, más pasivas que activas y proactivas y de baja involucración con la situación real del estudiante. Algunas de estas son:

- Orientar al estudiante sin imponer lo que "deben hacer".

- Brindar claridad sobre las instancias a las cuales recurrir o a los mecanismos legales que pueden ofrecer protección.

- Generar cero tolerancia hacia este tipo de intolerancia.

Varios profesores persisten en señalar la inexistencia de instancias que apoyen la mediación del conflicto y no logran percibirse como promotores de la resolución de conflictos en los estudiantes.

En todo caso, las respuestas de los profesores se inscriben en la dimensión discursiva de la práctica pedagógica. Visiblemente los docentes entrevistados pueden establecer relaciones con términos o referentes teóricos y legales que promueven la convivencia ciudadana, pero la proyección de esas concepciones a la acción no es tan clara.

\section{Grupos focales con estudiantes}

Como se explicó anteriormente, la recolección de información de estudiantes permitió ampliar la comprensión del contexto de la formación ciudadana planteado por los estudiantes, además facilitó el contraste de las acciones manifestadas por los profesores como "promotores de la formación integral y ciudadana" desde la mirada de sus estudiantes. 
En primer lugar, logró establecerse que para la gran mayoría de estudiantes participantes, la percepción sobre el conflicto se relaciona con la agresión física. Una menor proporción de estudiantes manifestó la diferencia de opiniones como definición de conflicto. Sin embargo se señaló a la intolerancia como la manifestación principal de este tipo de situaciones.

De otra parte, la discusión se centró en la necesidad de incluir este tipo de escenarios y los mecanismos para su solución en el reglamento estudiantil en contraste con el desconocimiento del reglamento. Esta mirada sitúa a los estudiantes desde la apreciación de la norma como un camino ideal, pero no esperado para lograr la convivencia.

En términos generales, se desestima el conflicto físico y se aprecia el conflicto de ideas (debate o disputa de ideas) como el único que verdaderamente puede promover la academia.

En relación con la participación, los estudiantes se concentraron en las manifestaciones de la democracia representativa y la dinámica de los órganos de gobierno estudiantil. Entre las manifestaciones de este tipo de participación se identificaron: el derecho al voto, la existencia de elecciones y la posibilidad de hablar con el Rector.

Ya en lo que se refiere a la pluralidad y el reconocimiento de las diferencias, el grupo focal describe una amplia gama de ejemplos que explican la noción de estos dos conceptos: actuar diferente, pensar diferente y respetar estos comportamientos en los demás (y esto trasladado a todos los aspectos de la vida).

Al buscar argumentación sobre esta respuesta, los estudiantes apuntan que este tipo de reconocimiento del otro es también una forma de valorar todo lo que puede aportar y ofrecer para enriquecer el entorno.

Otro aspecto importante fue el manejo de situaciones que amenazan los principios de- mocráticos, para el cual los estudiantes manifestaron la importancia de escuchar a una persona discriminada o excluida, evitar las salidas extremas (refiriéndose al suicidio) y conocer varios puntos de vista.

Como puede observarse, las respuestas de los estudiantes están muy relacionadas con los planteamientos de los estudiantes. También predomina el elemento discursivo y se privilegian las situaciones generales en lugar de las situaciones específicas o vividas por los actores. Sin embargo, es importante destacar que los estudiantes describen con más claridad el principio de la pluralidad que sus profesores, esta maduración en la interiorización del concepto podría explicarse por la exposición que tienen los estudiantes a pares que presentan diversidad de características y condiciones.

\section{Grupos focales con profesores}

El elemento dinamizador del diálogo dentro del grupo focal de profesores fueron las respuestas de los estudiantes participantes en el grupo focal. Sin embargo, la aplicación del grupo focal en profesores se enfocó en identificar los mecanismos que utilizan para describir o explicar situaciones relacionadas con la formación ciudadana.

Un aspecto detectado fue el uso de casuística para describir o explicar concepciones y prácticas. El uso de este mecanismo puede explicar la recurrencia al relativismo o la dificultad para establecer acuerdos que permitan analizar un contexto, situación o práctica.

Otro aspecto fundamental que se detectó fue la deliberada separación entre la "vida cotidiana" y la "vida profesional". Esta separación podría estar afectando negativamente la identificación de oportunidades para trasladar los saberes basados en referentes teóricos (contenidos) a la actuación en situaciones cotidianas.

Ya en lo que se refiere a las situaciones amenazantes de los principios en el aula, las res- 
puestas remiten a la ejemplificación de situaciones particulares sin establecer una conexión con el diseño de estrategias que conlleven la solución o mitigación de las mismas. Esta postura ante el conflicto y las situaciones de riesgo muestra los comportamientos de evasión del rol de mediador en el aula.

\section{Observaciones de clase}

Parte fundamental de la aplicación de este instrumento de recolección de información es que para los profesores de las UTS fue percibido como una herramienta para identificar conflictos y amenazas a los principios democráticos en el aula de clases. Sin embargo, es importante preguntarse ¿por qué el profesor considera que la detección de este tipo de situaciones en el aula debe hacerla un sujeto externo?

Los elementos más sobresalientes de las observaciones de clase redundan en la aplicación de normas para regular el control de la clase por parte del profesor. Lógicamente, la aplicación rigurosa de las normas de control (silencio, disposición de los cuerpos, insistencia en la atención) afecta la participación de los estudiantes, principalmente en la negociación sobre la dinámica de la clase (cuando esta no es lo suficientemente activa), el uso de equipos electrónicos y de la palabra.

La aplicación reiterada de la norma como mecanismo de control es una característica del rol tradicional del profesor y por lo general juega en contra del desarrollo de la autonomía y la autorregulación porque incorporan en los sujetos la necesidad de ser controlado y regulado.

Otro elemento observado es la relación entre profesor y estudiante cuando el primero cree que el segundo no se está "esforzando lo suficiente" para alcanzar su aprendizaje. Nuevamente esta concepción pertenece a la visión tradicional de la educación en la que el profesor comparte su sabiduría y el estudiante debe estar "dispuesto" a recibirla, recordarla y reproducirla. Sin embargo, en una observación de clase se hace explícito el llamado de atención de un estudiante sobre la subvaloración que hace el profesor de los "repitentes de la asignatura" en relación con su bajo desempeño. Esta situación puntual, en la que el estudiante reclama desde su sentir una actitud de que el profesor está evidenciando el uso de mecanismos de discriminación para controlar la clase.

Sobre el mismo riesgo a los principios democráticos se observó que en una clase el profesor hace referencia a "todos" los miembros de una tribu urbana, destacando que uno de sus estudiantes presentes (perteneciente a esta tribu) es la excepción. Este comportamiento del profesor evidencia el uso de estereotipos como forma de relación con sus estudiantes y puede ser nocivo para los procesos de desarrollo y consolidación de la identidad.

Volviendo a la participación, en varias observaciones de clase es notorio el esfuerzo que debe hacer el profesor para que sus estudiantes participen. Este comportamiento de los estudiantes puede explicarse, como anteriormente se dijo, en el exceso del recurso de control y regulación de la clase por parte del profesor, principalmente en el uso de la palabra.

En todas las observaciones de clase se identificó que el profesor reitera en su discurso la no discriminación de los estudiantes en las UTS, la importancia de la participación y del reconocimiento del otro. Sin embargo, los comportamientos descritos anteriormente hacen que la práctica pedagógica del profesor se inscriba en la dimensión comunicativa (discursiva) y difícilmente se refleje en sus acciones (práctica).

\section{Resultados}

Tres fueron los objetivos específicos trazados en la investigación que da cuenta el presente artículo. Los tres giran en esencia en la búsqueda de la identificación de las representaciones sociales que sobre competencias ciudadanas tienen los docentes y estudiantes de las Unidades Tecnológicas de Santander; ade- 


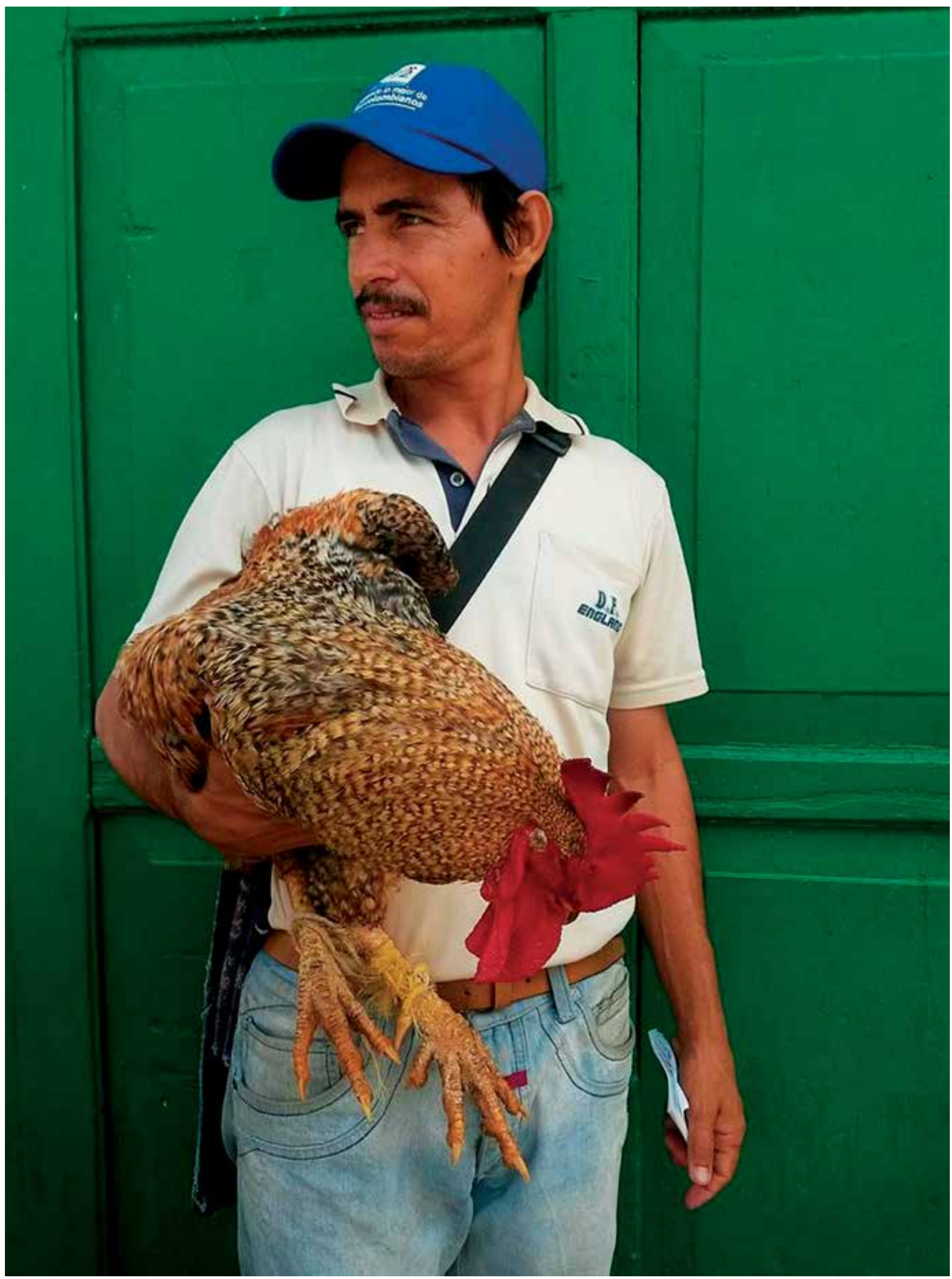


más, describir las prácticas pedagógicas que en relación con las competencias ciudadanas esta institución posee $y$, finalmente, contrastar las representaciones sociales con las prácticas pedagógicas de las UTS, en relación con las competencias ciudadanas. Por ello, las conclusiones que a continuación presentamos, se obtuvieron a través de exhaustivas entrevistas y grupos focales realizados con estudiantes y profesores. Las respuestas fueron objeto de un análisis hermenéutico y de la contrastación, que nos lleva a plantear las siguientes conclusiones:

Dentro de las representaciones sociales que configuran el quehacer educativo y pedagógico, los maestros conciben el conflicto como un desacuerdo entre dos o más personas; o como una agresión verbal o física. También se nomina al conflicto como una ausencia de consenso o una situación fuera de lo normal que impide a los ciudadanos sobrellevar de manera normal la cotidianidad.

Como los profesores no tienen claridad sobre procedimientos de intervención educativa ante el conflicto, se recurre a propuestas que tienen como objetivo, aumentar la malla curricular, esto es, la creación de una cátedra especializada en resolver los conflictos. Soluciones que no van a la esencia de la consolidación de ambientes de discusión lúcida y razonable. Otra situación adversa y casi extrema, de acuerdo con las respuestas de los docente entrevistados, es que el docente evade la responsabilidad de servir como mediador entre los conflictos estudiantiles. Esto evidencia que los docentes no poseen formación para una adecuada resolución de conflictos. Ello es atribuido a la ausencia de una política educativa homogénea al respecto.

Además, el concepto de estrategia tiende a confundirse con el concepto de habilidad o de valores como respetar y escuchar. En consecuencia, no existe una planeación de estrategias para la resolución de conflictos, esta ocurre de manera espontánea o a través del estilo de cada docente. Es así como hay quienes manifiestan que, incluso, existen docentes que provocan el conflicto en contraposición a aquellos docentes que se hallan en permanente actitud de comunicación y diálogo.

En relación con conceptos como pluralidad, se percibe un alto grado de confusión e imprecisión semántica que los lleva a dudar del término $y$, en consecuencia, de la competencia ciudadana. Así, encontramos que la pluralidad entendida como el reconocimiento de la diversidad, es confundida por los docentes entrevistados con la equidad, es decir, la posibilidad de tener igualdad de condiciones de acceso a la educación, a la cultura, a los viajes.

Tanto docentes como estudiantes consideran el aula como un espacio para transmitir conocimientos y no para generar procesos de identidad, porque están convencidos de que en las Unidades Tecnológicas existe respeto hacia el ser diferente: la Universidad, se precia, en palabras de los docentes y estudiantes, de recibir sin distingo a estudiantes de toda clase social y de todas las tendencias religiosas y orientaciones sexuales. Estas concepciones, a nuestro parecer, encajan mejor en la pregunta por la diversidad, pero surgen en este punto relacionado con la identidad.

Es coherente, por consiguiente, que la exclusión sea configurada por maestros y estudiantes de las Unidades Tecnológicas de Santander como consecuencia del poco conocimiento sobre el contexto. La exclusión no es una práctica común en esta Universidad, pues consideran que es un imaginario colombiano, la presunción, los prejuicios que llevan a excluir a los estudiantes: el color de una camisa, las llegadas tarde (entonces son irresponsables). Plantean sobre este aspecto que desde el aula se debe trabajar para acabar con la ignorancia y los prejuicios. La considera una injusticia, quizás la peor que se ha inventado el ser humano. En general, se cree que la exclusión social también es generada por la actitud de autocompasión y 


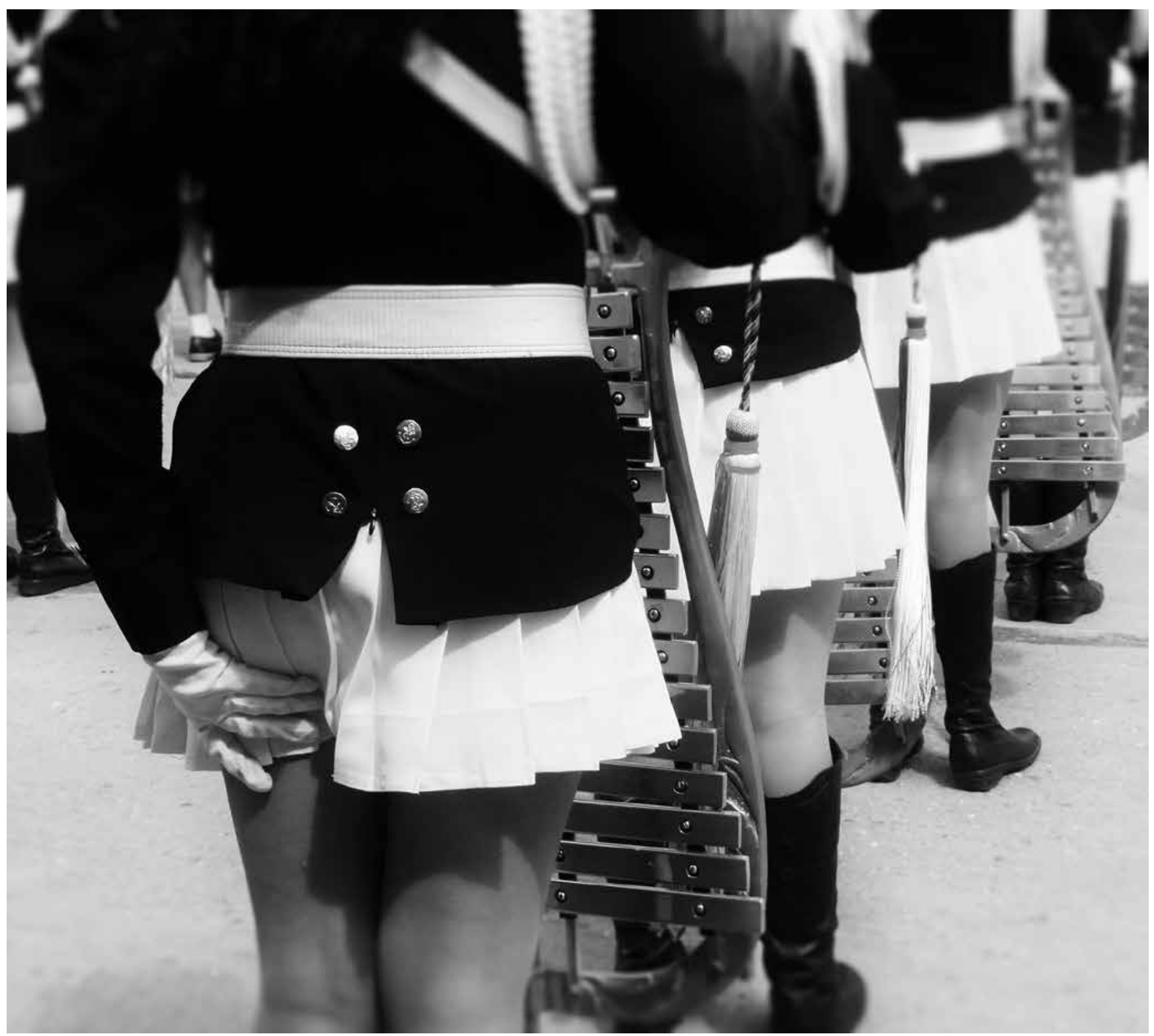

de facilismo de los estudiantes que están en el sitio más bajo de la pirámide social.

Pero fluyen los contrasentidos y se observa la configuración de la exclusión y la discriminación como un acto inconcebible. La mayoría de los docentes entrevistados emplean las cátedras que tienen bajo su responsabilidad para generar diálogos alrededor de la discriminación y la exclusión. Por ello mencionan el análisis de diferentes tipologías textuales (columnas, cortometrajes) para poner sobre la mesa académica estos temas. También se nota que son conscientes que estos temas deben ser transversa- les y no solo un requisito de asignatura sino una actitud ante la cotidianidad que se resume en una práctica: el respeto por el otro.

La categorización realizada a partir de las entrevistas y grupos focales con estudiantes, se centra más en lo emotivo y comunicativo que en lo cognitivo de cada una de las competencias ciudadanas sobre las cuales se indagó.

\section{Conclusiones}

La información recolectada y analizada permite entrever acciones en las que la práctica pedagógica del docente se desconecta, por 


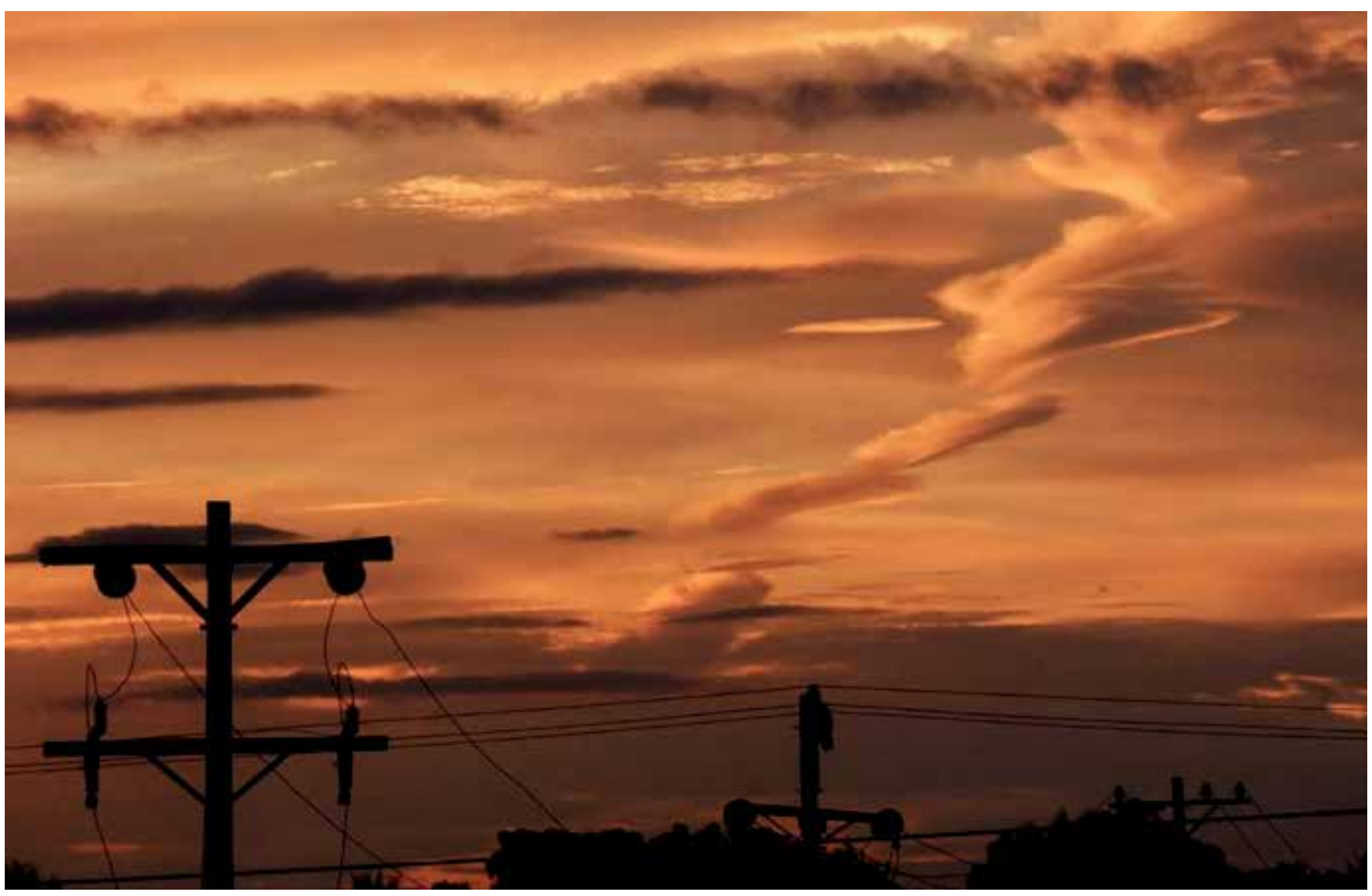

momentos, de las representaciones sociales sobre la formación ciudadana. Tal vez el principal hallazgo que explica esta situación es la desconexión entre la "vida laboral" y la "vida cotidiana", que no le permite al profesor identificar oportunidades reales de formación en situaciones y comportamientos que se presentan en el diario vivir. En gran parte, el profesor de las UTS se enmarca en la dimensión cognitiva descrita por Chaux y no logra anticipar en su propia actuación los riesgos que amenazan a la incorporación de los principios pedagógicos.

De otra parte, se detectó la importancia de vincular a los estudiantes en la identificación de las prácticas pedagógicas de sus profesores, pues en sus concepciones se pueden develar la transferencia de concepciones y creencias que le ha legado el profesor durante el proceso de formación. Seguramente más ejercicios de investigación que contemplen el abordaje de esta población ofrecerán elementos de análisis muy enriquecedores para la discusión.

Finalmente, y teniendo en cuenta las dificultades de acceso a la población de profesores por el recelo que ellos experimentan en cuanto a compartir su práctica pedagógica, es necesario plantear estrategias más efectivas para la participación de más sujetos en este tipo de estudios, pues más que una exposición maliciosa de las debilidades del maestro se observan aportes importantes que pueden motivar y orientar la propia reflexión del profesor sobre su práctica, la generación de aprendizajes pedagógicos que lo lleven a relacionarse mejor con sus estudiantes y el diseño de estrategias desde sus propias experiencias en el aula para motivar un aprendizaje real de la ciudadanía. 


\section{Referencias}

Aldana, G., Ruiz, J. (2010). La formación por competencias y la calidad de la Educación. Entrevista al Ph.D. Sergio Tobón Tobón. Revista Teoría y Praxis Investigativa, 1,(5), 13-17.

Aldape, T. (2008). Competencias del docente siglo XXI. Desarrollo de las competencias del docente: demanda de la aldea global siglo XXI. México: Libros en red.

Bisquerra, R., \& Pérez, N. (2007). Las competencias emocionales. Educación XXI: Revista de la Facultad de Educación, (10), 61-82.

Boza, A., Méndez, J., Monescillo, M., y Toscano, M. (2010). Educación, investigación y desarrollo social (p. 35). España: NARCEA.

Bustos, A. (2010). Desarrollo, aprendizaje y enseñanza en la educación secundaria. España: Ministerio de Educación.

Chaux, E., Lleras J., \& Velásquez, A. (2004). Competencias ciudadanas: De los estándares al aula. Una propuesta de integración a las áreas académicas. Bogotá. MEN Ediciones Uniandes.

Chaux, E. (2004). Competencias ciudadanas: ¿Qué son las competencias ciudadanas? Colombia Aprende. Colombia: Ministerio de Educación Nacional. Recuperado de http://www.colombiaaprende.edu.co/html/ home/1592/article-96635.html.

Cox, C. (2010). Sistema regional de evaluación y desarrollo de competencias ciudadanas - SREDECC. Recuperado de http://www.mineducacion.gov.co/1621/articles246644_archivo_pdf_resumen_ejecutivo_refnacional.pdf

Delgado, R., \& Vasco, C. (2003). Interrogantes en torno a la formación de las competencias ciudadanas y la construcción de lo público. Artículo de reflexión, ponencia presentada en el marco del Doctorado en Ciencias Sociales Niñez y Juventud, Universidad de Manizales - CIN$D E$, en el Simposio Internacional de Investigación realizado en Manizales desde 19 al 26 de agosto de 2003.

Denyer, M. (2009). Las competencias en la educación: un balance. México: Fondo de Cultura Económica.

Escalona, A., Loscertales, B. (2009). Actividades para la enseñanza y aprendizaje de competencias genéricas en el marco del espacio europeo (p. 19). España: Universidad de Zaragoza.

Figuera, P., y Rodríguez, M. (2008). Una formación para el empleo. En Reflexiones en torno al balance de competencias. Concepto y herramientas para la construcción del proyecto profesional. España: Universidad de Barcelona.

Goleman, D., Mckee, A., y Boyatzis, R. (2002). Liderazgo primario. Descubriendo el poder de la inteligencia emocional.

Gurdián-Fernández, A. (2007). El paradigma cualitativo en la investigación socio- educativa. Colección IDER: San José de Costa Rica.

Hymes, D. (1996). Acerca de la competencia comunicativa. Forma y función, 9. Departamento de Lingüística, Universidad Nacional.

Jaramillo, R. (2004). Las competencias ciudadanas nacional marzo 2004. Altablero, 27. Periódico del Ministerio de Educación.
Magendzo, A. (2006). Educación en derechos humanos: un desafío para los docentes de hoy (p. 7). Chile: LOM Ediciones.

Marco, B. (2008). Competencias y contexto. Competencias básicas: Hacia un nuevo paradigma educativo (p. 39). España: NARCEA.

Medina, A., \& Muñoz, A. (2011). Uno no escoge lo que va a pasar mañana. Vivencias y significados en torno a las competencias ciudadanas de convivencia y paz en estudiantes de séptimo grado, en la Institución Educativa Jesús Rey. Medellín: Universidad de San Buenaventura.

Mejía, A., \& Perafán, B. (2006). Para acercase al dragón, para amansarlo, es necesario haberlo amansado primero: una mirada crítica a las competencias ciudadanas. Revista Estudios Sociales, 23, 23-35.

MEN. (2004). Estándares básicos de competencias ciudadanas. Colombia: Ministerio de Educación Nacional.

MEN. (2004). Formar para la ciudadanía... jsí es posible! Lo que necesitamos saber y saber hacer. Cartilla guía 6. Bogotá: Ministerio de Educación Nacional.

MEN. (2002). Programa de educación para el ejercicio de los derechos humanos. Eduderechos. La educación para el ejercicio de los derechos humanos en la escuela: Un compromiso de todos. Ministerio de Educación Nacional. Programa de Revolución Educativa 2002-2010.

Mestre, J.M., Guill, M.R., Carreras de Alba, M.R., y Braza, P. (noviembre, 2000). Cuando los constructos psicológicos escapan del método científico: el caso de la inteligencia emocional y sus implicaciones en la validación y evaluación. Revista Española de Motivación y Emoción, 4(3). Recuperado de http://reme.uji.es

Mieles, M., \& Alvarado, S. (2012). Ciudadanías y competencias ciudadanas. Revista Estudios Políticos, 40, 53-75. Instituto de Estudios Políticos, Universidad de Antioquia.

Mockus, A. (febrero-marzo, 2004). ¿Por qué competencias ciudadanas en Colombia? Apuntes para ampliar el contexto de la discusión sobre estándares y pruebas, que en competencias ciudadanas ha empezado a construir y aplicar el Ministerio de Educación. Revista electrónica Al tablero, 27.

Panchón, C. (2007). Modelos educativos alternativos que conllevan el reconocimiento y el respeto por el otro. Revista de Educación, 342, 147-166. Ejemplar dedicado a: Violencia de género y relaciones de poder: implicaciones para la educación. Recuperado de http://www. revistaeducacion.mec.es/re342/re342_08.pdf

Restrepo, J.C. (enero-junio, 2006). Estándares básicos en competencias ciudadanas: una aproximación al problema de la formación ciudadana en Colombia. Papel Político, 1,(11), 137-175. Pontificia Universidad Javeriana Colombia. Recuperado de http://www.redalyc.org/articulo.oa?id=77716566006)

Ríos, C. (sep.-dic., 2000). Ciudadanos del mundo. Hacia una teoría de la ciudadanía, 28,(XII), 119-123.

Ruiz-Silva, A., Chaux, E. (2005). La formación de competencias ciudadanas (1a. ed.). Colombia: Asociación Colombiana de Facultades de Educación - ASCOFADE.

Soriano, E. (2006). Competencias ciudadanas en el alumnado de segundo ciclo de educación secundaria obligatoria de Almería. Revista de Investigación Educativa, 24(1), 119- 146. 
Tobón, S. (2006). Aspectos básicos de la formación basada en competencias. Talca: Proyecto Mesesup. ECOE Ediciones. Bogotá.

Tobón, S. (2010). Formación integral de competencias. Pensamiento complejo, currículo, didáctica y evaluación. Instituto CIFE. Ecoe Ediciones.

Vélez. L. (mayo, 2011). La formación ciudadana y/o la formación del ciudadano. "Una reflexión obligada hoy". Revista Reflexión e Investigación, 3. Revista Editorial del Congreso por una Educación de Calidad. Fondo Editorial del Caribe. Cartagena de Indias. Recuperado de www. porunaeducaciondecalidad.org

Villardón, L. (2008). La planificación del currículo. En Planificar desde competencias para promover el aprendizaje (p. 21). España: DEUSTO.
Walzer, M. (1996). La política de la diferencia: Estatalidad y tolerancia en un mundo multicultural. ISEGORíA 14, 3753. Institute for Advanced Study, Princeton. (Trad. Rafael del Águila). Recuperado de http://isegoria.revistas.csic. es/index.php/isegoria/article/view/210/210

Yániz, C., Villardón, L. (2011). Planificar desde competencias para promover el Aprendizaje (p. 17). España: DEUSTO.

Zabala, A., y Arnau, L. (2007). 11 ideas clave: cómo aprendery enseñar competencias. España: GRAO.

Zubiría, S. (2002). La mala pedagogía se hace con buenas intenciones. En G. Bustamante et al. (Eds.). El concepto de competencia II: Una mirada interdisciplinar. Bogotá: Sociedad Colombiana de Pedagogía. 